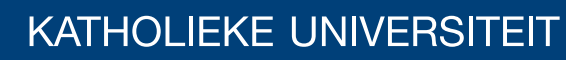 \\ LEUVEN
}

\section{Faculty of Business and Economics}

6XSSDIFKDLQP DQDJHP HQVRIIERRRSLRGXFW] DIOADUXHUHMLE

- HWRQ\%H(SQDQQG+ HQ) RLFp

DEPARTMENT OF DECISION SCIENCES AND INFORMATION MANAGEMENT (KBI) 


\title{
Supply chain management of blood products: a literature review
}

\author{
Jeroen Beliën ${ }^{1,2, *}$, Hein Forcé \\ ${ }^{1}$ Hogeschool Universiteit Brussel, Faculty of Economics and Management, Research Center for Modelling and Simulation, \\ Stormstraat 2, B-1000 Brussels, Belgium, 0032(0)26098271, jeroen.belien@hubrussel.be \\ ${ }^{2}$ Katholieke Universiteit Leuven, Faculty of Business and Economics, Department of Decision Sciences and Information \\ Management, Research Center for Operations Management, Naamsestraat 69, B-3000 Leuven, Belgium \\ *Corresponding author
}

This paper presents a review of the literature on inventory and supply chain management of blood products. First, we identify different perspectives on approaches to classifying the existing material. Each perspective is presented as a table in which the classification is displayed. The classification choices are exemplified through the citation of key references or by expounding the features of the perspective. The main contribution of this review is to facilitate the tracing of published work in relevant fields of interest, as well as identifying trends and indicating which areas should be subject to future research.

Keywords: OR in health services, Supply chain management, Inventory, Blood products, Literature review

\section{Introduction}

The management of blood is a problem of specific concern for the human race. Even though there are technological developments in the field of substitutes for blood products, the need for donor blood and its derived products will always exist.

Blood is not an ordinary commodity. The supply of donor blood is fairly irregular and the demand for blood products is at least as stochastic. Matching supply and demand in an efficient manner is not straightforward. Blood products are also perishable, which complicates things even further. Shortages lead to high costs for society, since they can cause increase mortality rates. Outdates on the other hand are not commonly accepted either, since blood donors are a scarce asset of society and donors must respect a certain time period between two donations, depending on the type of donation. Also, only a small percentage (5\%) of the eligible donor population actually donates(1)(2). That is why we deemed it necessary to include some papers about donor psychology and motivation in this paper, even though this is not strictly within the field of operations management.

Concerning the supply management of blood products, it is impossible to talk about blood as a product on its own. To put things simply, blood is usually drawn in its whole and undivided form (in the remainder of this paper referred to as 'whole blood') from donors. Some components, such as blood platelets, can also be obtained directly from the donor without drawing blood. In this case, the 
donor is connected to an apheresis device through which the donor's blood circulates. The machine can filter the desired components from the blood while the remaining components flow back into the donor. The extraction of platelets by this process is costlier, however, than obtaining them from donated whole blood (3). The latter method is less usual, but we have included some papers which apply this technique. Once the whole blood is drawn, it is usually centrifuged into three major components: red blood cells, plasma and blood platelets. The different components have different shelf lives and the separation enables one to adapt the use of blood products to the specific needs of a patient. For instance, blood plasma is used to treat burns (4).

We primarily focus on these components in this paper and we have also included papers regarding frozen blood components. The products are further distinguished by means of different blood groups and the Rhesus factor. We did not focus on the areas of cord blood banking and the inventory management of stem cells. These are related products with similar characteristics to the components discussed in this review, but we decided to narrow our scope to the more widespread components.

The papers in this review are particularly relevant for blood banks, which are institutions that collect blood, perform a screening test and label the products with the appropriate blood group. Blood banks can be organized in multiple manners, ranging between the two extremes of centralization and decentralization.

We have encountered only one literature review during our research. This literature review written by Nahmias (5) deals with perishable inventory problems as a whole instead of focusing on blood products. The review is not recent (1982) and deals merely with inventory problems instead of considering the entire supply chain. It does include a brief review of the application of the discussed models to blood bank management. In the book Operations Research and Health Care: A Handbook on Methods and Applications, Pierskalla et al. (3) present a very interesting overview paper, which is probably one of the most widely read papers in the area of blood supply chain management. Pierskalla's paper describes strategic models for assigning donor areas and transfusion centers to community blood centers, determining the number of community blood centers in a region, locating these centers and coordinating supply and demand, as well as models for tactical and operational issues in collecting blood, inventory management, blood allocation to hospitals, blood delivery and crossmatching. Although Pierskalla's paper contains a short literature review section and describes several models, it is not a literature review paper. We believe our paper is relevant in the sense that it is an attempt to classify the existing literature concerning blood supply chain problems, with the purpose of guiding people to papers relevant to their field of interest. As Pierskalla (3) states:

'The entire blood supply chain can be examined as an essentially whole system and not just a subsystem of some larger system as occurs in most other supply chains.'

This statement suggests that the problem is rather different from other supply chain problems, and that it might be worthwhile to investigate how the blood supply chain problem can be decomposed into different sub problems. We try to map the literature according to different criteria. In the meantime, 
we made an effort to identify trends and lessons learned from various case studies. We did not incorporate a lot of papers dealing with technological issues, though we consider a few of them, because it would be wrong to ignore the possible advantages that might arise from using these technologies. Nevertheless, the focus is merely on the managerial viewpoint.

We searched the databases Web of Science, Pubmed, Academic Search Premier, Business Source Premier, Econlit and SCIRIUS for relevant papers on inventory and supply chain management of blood products. References cited in the obtained manuscripts were reviewed to find additional publications. We ended up with a total set of 98 manuscripts. To illustrate the distribution of the papers according to publication date, we included a distribution diagram in Figure 1. Two peaks are visible in the diagram, i.e. in the period 1976-1985 and more recently in the period 2001-2010.

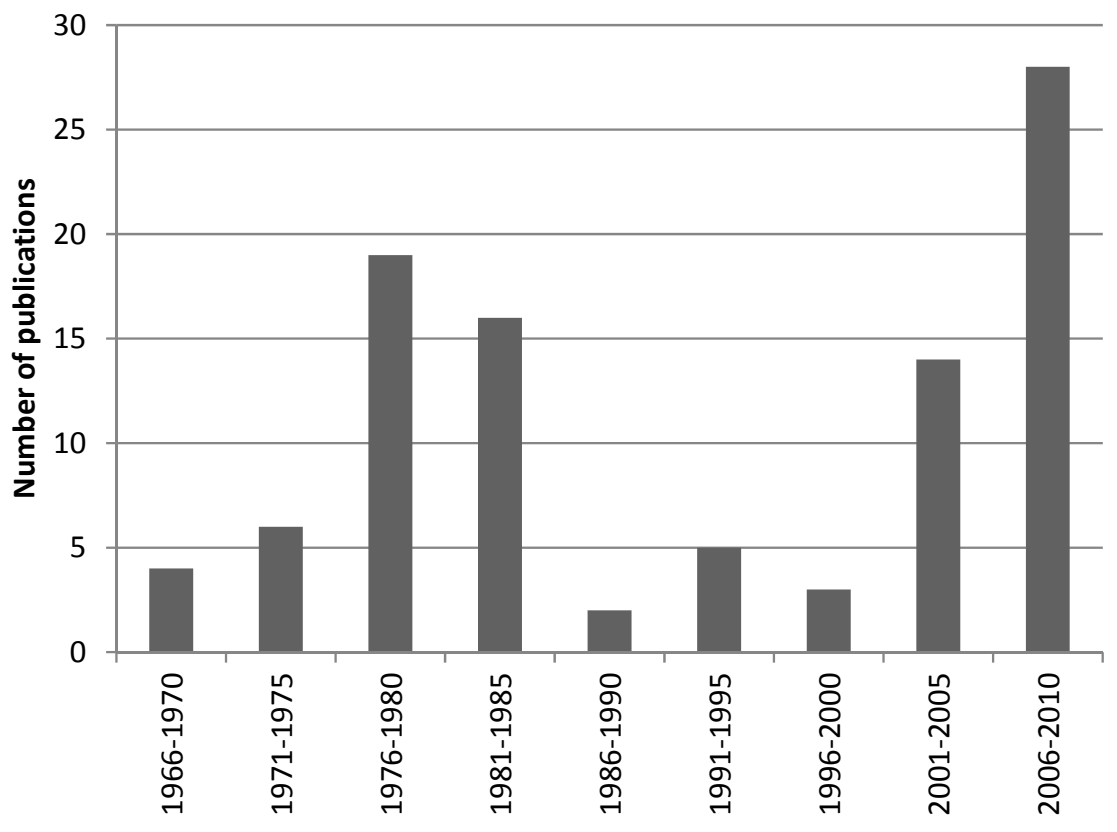

Figure 1: Number of publications by publication period

We structured the literature review using different perspectives. That way, a researcher can query a list of manuscripts according to his specific needs. For instance, a reader wanting to learn more about the virtues of centralization should not use a taxonomy based on type of blood product. And a taxonomy based on hierarchical level is not efficient for a researcher looking for information about blood platelet problems. The classification fields are the following:

1) Type of blood product (section 2)

2) Solution method (section 3)

3) Hierarchical level (section 4) 
4) Type of problem (section 5)

5) Type of approach (section 6)

6) Exact versus heuristic (section 7)

7) Performance measures (section 8)

8) Practical implementation/case studies (section 9)

\section{Type of blood product}

We distinguish between the following types of products: whole blood, red blood cells, blood platelets, blood plasma and frozen blood. All of these components are perishable, except for plasma(6). Papers handling white blood cells or other components are not included in this review. The frozen blood is mainly frozen red blood cells. One paper mentions fresh-frozen plasma and sometimes it was not that clear what was meant by frozen blood. We suppose it concerns frozen red blood cells, since this is the most commonly used blood product (6). Other papers just talk about 'blood', so we cannot be sure what the focus of the paper is. Those papers belong to the category 'unclear'. Nevertheless, most papers are clear about which blood products they are considering, so we think this is a useful perspective for classifying the literature. Table 1 lists the papers according to the type of blood product.

\subsection{What is the purpose of the components?}

The components are generally extracted from the collected whole blood, and are used in different cases when treating patients. Red blood cells are used in surgery in the event of major blood loss, but they are also used to treat anemic patients and premature infants. Platelets too are used in the event of major blood loss, but are also needed for the treatment of cancer. Blood plasma is the third component that is used to curb (or cope with) blood loss in surgery. It also has an application in treating liver diseases and burn injuries (4).

\subsection{Whole blood and red blood cells (RBC)}

The difference between whole blood and red blood cells in the paper is particularly small. Often, the authors use the term 'blood' when they mean 'red blood cells'. The mixing up of these terms is very common, but this is probably due to the fact that red blood cells are the blood components most in demand. In cases of doubt, we preferred the term 'whole blood' when the paper handles donor issues, since most blood is collected as whole blood and only separated into components afterwards. Furthermore, when the authors deliberately mention the differences between blood groups, we assumed that red blood cells are the relevant components in those cases. Since the blood group is determined by the antigens on the surfaces of the red blood cells, we believe this is not an 
unreasonable assumption. We do have to admit that blood platelets (PLT) differ in terms of blood groups, but since these components are more complex than RBC because of their shorter shelf life, we are sure the authors would have mentioned whether they are dealing with a PLT-problem or not (4). Historically, whole blood and red cells account for the largest proportion of blood transfusions (6). This is confirmed by our classification: most papers, we found, are placed in these two categories. However, many papers are not recent, and this distribution among categories might not entirely reflect the relative importance of the different blood products today.

\subsection{Plasma}

Not many papers dealing with the plasma product were encountered. Only a few papers mention this component, and even those papers did not really focus on the plasma supply chain in depth. Probably this is due to the fact that handling a plasma inventory is significantly less complex than any other component's inventory, bearing in mind the long shelf life of the product (7). It seems that when freezing components, plasma has an advantage over red blood cells in terms of time, throughput and cost of processing (8). Perhaps this is why Prastacos (6) states that plasma is the only 'not perishable' component of blood. Freezing plasma is a good way of maintaining a reasonable inventory, but one still has to consider a 20-minute thawing time, which could be too long in an emergency. In practice, it is common to maintain a stock of 5-day thawed frozen plasma to anticipate general and emergency use (8).

The literature suggests that all plasma is frozen after extraction from whole blood (4). This means that papers dealing with plasma in a sense automatically deal with freezing blood.

Table 1 - Type of blood product

\begin{tabular}{|c|c|}
\hline $\begin{array}{l}\text { red blood } \\
\text { cells }\end{array}$ & $\begin{array}{l}(3)(9)(1)(10)(6)(11)(12)(13)(14)(15)(16)(17)(4)(18)(19)(7)(20)(8)(21)(22)(23)(24)(25 \\
)(26)(27)(28)(29)(30)(31)(32)(33)(34)(35)(36)(37)(38)(39)(40)\end{array}$ \\
\hline $\begin{array}{l}\text { blood } \\
\text { platelets }\end{array}$ & $(1)(6)(16)(4)(18)(7)(20)(27)(41)(42)(43)(44)(45)(46)(47)(48)(49)(39)(50)(40)$ \\
\hline plasma & $(6)(4)(18)(7)(39)$ \\
\hline whole blood & $\begin{array}{l}(6)(3)(11)(13)(19)(29)(5)(51)(52)(53)(54)(55)(56)(57)(58)(59)(2)(60)(61)(62)(63)(64 \\
)(65)(66)(67)(68)(69)(70)(54)(39)(50)(40)(71)(72)\end{array}$ \\
\hline frozen blood & $(6)(5)(4)(9)(8)(32)(33)(73)(39)$ \\
\hline other/unclear & $\begin{array}{l}(74)(75)(76)(77)(78)(79)(80)(81)(82)(83)(84)(85)(86)(87)(88)(89)(90)(91)(92)(93)(9 \\
\text { 4)(95)(96) }\end{array}$ \\
\hline
\end{tabular}




\subsection{Frozen blood}

The product that is most often mentioned when talking about freezing blood is frozen red blood cells. Red blood cells can be stored for multiple years by freezing them. After thawing, the shelf life is limited again, ranging from one day to two weeks depending on the system used. In order to protect the red blood cells from the adverse affects of freezing (formation of crystalline ice, which disrupts the cell membranes), glycerol is added to this biological fluid. But the adding of a cryoprotectant to a biological fluid also means that the cells have to be washed after thawing. The whole process is rather time-consuming and a unit of deglycerolized RBC costs three to four times as much as the unit of RBC from which it is made (8). The efficiency of maintaining a frozen red blood cell inventory seems rather low in most cases. Hess (8) mentions some real life examples of how a frozen RBC inventory fails to be adequate. These examples mention the higher costs and the phenomenon of doctors refusing to use the thawed units, because they deem the quality insufficient, as the most important disadvantages. Red blood cell freezing does prove useful in cases of autologous red blood cell storage. Another reason it is commonly used concerns its role in preserving units of a rare phenotype, but this need can be fulfilled also by maintaining lists of donors with rare phenotypes. These donors then should be available to donate for elective cases. Prastacos (6) mentions a rather unexpected advantage of using frozen blood. He reports that it has been shown that freezing-thawing techniques provide red blood cells superior in oxygen transport capability than those of fresh blood. Both advantages and disadvantages should be considered in a blood inventory model in order to determine whether maintaining a frozen blood reserve is an efficient practice in a particular situation. The overall tendency, as observed by Hess, (8) is that red blood cell freezing will continue to be used, but at a decreasing rate.

\subsection{Blood platelets (PLT)}

We included substantially fewer papers about blood platelets, compared to red blood cells and whole blood. As mentioned before, the problem with platelets is that they have a very short shelf life compared to other products. This leads to increased complexity, and based on the papers we read about the problem, further research might be in place here. A striking fact that we encountered during our research is the phenomenon of Blake (44) criticizing the paper by van Dijk et al.(42). The latter paper seemed very promising and is fairly recent (2009). It introduces an innovative solution approach, closing a gap in the literature which has existed for a long while due to the complex nature of the problem. Blake (44) acknowledges their work as a worthy attempt to solve a PLT inventory management problem, but fails to share their enthusiasm with their results and explains why. Van Dijk et al. (42) formulate the perishable inventory problem via the dynamic programming (DP) technique. The problem is that it is very difficult to solve a DP model of realistic size. They dealt with this by suggesting a multistep procedure, combining simulation with dynamic programming. The order sizes are compared with those seen in a classic order-up-to policy, and then they select that 
order-up-to rule for each day that is most frequently seen in the simulated history. This could be a clever heuristic solution to the PLT ordering problem, but Blake (44) does not agree with the assumptions made. Van Dijk et al. (42) assumed that the age distribution of stock can be ignored, while Blake (44) proves this cannot always be ignored when placing an order. Blake (44) also notes that the proposed solution is not easily generalized. Furthermore, he noticed that their solution to the case example is infeasible too, but this is not his biggest concern. In fact, further research is necessary to develop robust and fast heuristics to solve the PLT inventory problem. There is no proof yet whether a solution to the PLT ordering problem exists involving simple order-up-to rules resulting in both low levels of outdate and wastage.

\subsection{Trends in type of blood product}

Figure 2 depicts the number of publications of each type of blood product over time. Although still four recent papers (2006-2010) just mention 'blood', the number of papers classified under 'Others/Not clear' has decreased significantly. In recent publications researchers present solutions for specific types of blood products. In particular, in the last five years there is a peak in publications on red blood cells and blood platelets. Considering the open research questions with respect to blood platelets (see Section 2.5), we believe that that this is a fruitful area for further research.

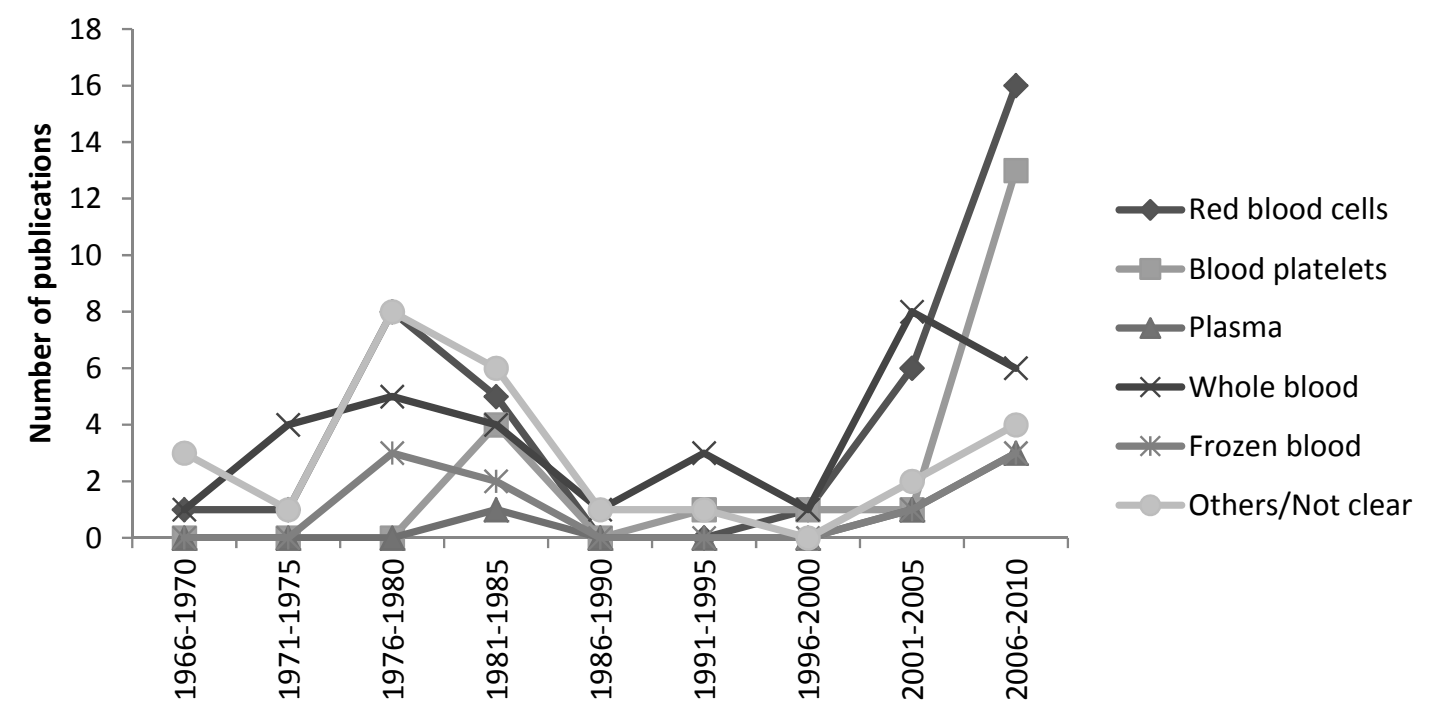

Figure 2: Trends in type of blood product 


\section{Solution method}

The list of solution methods encountered is rather diverse. A large number of papers is classified into categories such as simulation (this includes both discrete event and Monte Carlo simulation) and statistical analysis (linear regression, survival analysis, logistic regression, ANOVA...). Other papers are placed in operations research categories such as integer programming, linear programming and stochastic dynamic programming. Nine papers deal with queuing theory (mostly Markov chains) and another nine papers relate to evaluation and best practices (including DEA). Those are the categories most readers will be familiar with. The categories of custom spreadsheet and what-if scenario analysis are less straightforward for the reader. These capture the papers that fall in the leftover category, but that were interesting enough to include in this literature review. Table 2 lists the papers according to solution method.

\subsection{Evaluation/Best practices}

Pereira (10) utilizes a spreadsheet to compute his DEA models. He compares the levels of technical efficiency (the ability to transform inputs into outputs) rather than those of economic efficiency in relation to a sample of regional blood centers in the USA. He thereby distinguishes between scale efficiency and pure technical efficiency. Pure technical efficiency is that part of the efficiency score that cannot be explained by differences in scale. His main conclusion was that within the size range of blood centers included in his study, expanding the level of operations beyond a certain point leads to diminishing returns to scale. Also, he observed that most of the technical inefficiency he found in the centers operating under constant or increasing returns to scale was scale-independent. On the other hand, the technical inefficiency in centers operating under decreasing returns to scale seemed to be mostly size-related.

Pitocco and Sexton (18) analyze the efficiency of 70 blood centers in the US to determine the extent to which operational efficiency can be improved. Increasing the national blood supply by augmenting operational efficiency would be an alternative to increasing the collection and production of blood components. They perform a DEA, both input-oriented and output-oriented. Pitocco and Sexton formulate and solve the DEA model by linear programming. For a complete DEA, they solve a linear program for each unit. They found that half of the blood centers in the sample were efficient, while the inefficient ones can both increase outputs and decrease some inputs.

Heddle et al. (15) establish benchmarking targets for red blood cell outdating in hospitals. The results of their logistic regression identify different peer groups, facilitating the categorizing of hospitals in groups. Within these groups, benchmarking can be performed. They also used bubble plots for the purpose of identifying peers.

Perera et al. (16) identify examples of best practice regarding stock level and wastage in hospital blood banks. 
Table 2 - Solution method

\begin{tabular}{ll}
\hline evaluation/best practices & $(10)(15)(16)(18)(21)(25)(27)(38)(75)$ \\
simulation & $(14)(61)(26)(32)(42)(6)(41)(1)(12)(4)(19)(78)(79)(82)(64)(28)($ \\
& $83)(65)(46)(70)(33)(53)(3)(52)(17)(34)(40)(71)$ \\
queuing models & $(24)(31)(5)(6)(29)(23)(17)(34)(13)$ \\
stochastic dynamic programming & $(42)(6)(41)(44)(72)$ \\
integer programming & $(74)(87)(75)(76)(77)(50)$ \\
linear programming & $(18)(88)(6)(11)$ \\
statistical analysis & $(51)(15)(16)(54)(56)(57)(58)(59)(2)(60)(81)(62)(25)(26)(84)(67$ \\
cost analysis & )$(47)(90)(35)(92)(97)(6)(29)(70)(3)(63)(39)$ \\
(meta)heuristics & $(7)(81)(73)(67)(65)(53)$ \\
mathematical proofs/derivations & $(31)(52)(66)(68)(69)(39)(96)$ \\
what-if scenario analysis & $(20)(8)(36)$ \\
custom spreadsheet & $(66)(68)(69)(50)(72)(96)$ \\
other/unclear & $(22)(45)(30)(85)(86)(48)(49)(37)(91)(93)(94)(95)(80)(89)(39)$ \\
&
\end{tabular}

\subsection{Simulation}

In total, 28 papers use simulation as a solution method. This confirms the complexity of the problems at hand, since simulation is often applied in cases where it is rather difficult to find an optimal policy. Simulation is popular because it does not suffer from major computational problems and it allows for detailed results. The main disadvantage of the method is that it does not provide any guarantee of optimality. Also, the results reported are highly dependent on the specific situation of the case study and their simplifying assumptions. It is not always clear to what extent the results can be generalized. The robustness of the results is often difficult to verify too (41). The method itself boils down to trial and error scenario analysis based on experience and common sense, evaluating the effectiveness of a given rule rather than being an approach geared itself to obtaining a better rule (42). Often, the use of simulation leads to the detection of nearly optimal policies, which can be sufficient in a lot of cases where optimal decision making is impossible or impractical. The papers we have included concern 
both discrete event and Monte Carlo simulation, though most papers apply discrete event simulation. Kamp et al. (14) study case scenarios regarding the availability of blood products in the event of an influenza epidemic or comparable pandemic event. They work with a mathematical model and computer simulations to model the spread of influenza, the so called SIR model (susceptible-infectedrecovered model). After simulating several pandemic scenarios, they came to the conclusion that it is of crucial importance to identify the fraction of transfusions that cannot be postponed. They emphasize the importance of epidemic preparedness by suggesting the elaboration and implementation of a prioritization scheme for the release and use of blood products. This prioritization scheme should save critical resources at the beginning of the pandemic by prioritizing and postponing transfusions, leaving them available for later transfusion at the pandemic peak.

Jagannathan and Sen (52) utilize a simulation model written in Fortran to replicate daily transactions in a typical blood bank. These results are then used to corroborate the results obtained from their theoretical model.

Kopach et al. (17) construct a red blood cell inventory system with two demand rates. Their main method is an already existing queuing model, which they revisit so it can distinguish between urgent and non-urgent demand. They use simulation to compare the efficiency of the model with current control techniques, using real data obtained from the Canadian Blood Services.

Rytilä and Spens (4) try to increase the efficiency in blood supply chains by means of discrete event simulation. They state that there is a lack of work on computer simulations in blood supply chains, while they recommend the use of simulation to make this complex supply chain more comprehensible and efficient. They modeled and simulated 11 different scenarios, each of which focuses on other objectives. Scenario 2 for example focuses on the most effective use of blood units of a rare blood type by imposing the rule of only using blood of the patient's own type. Scenario 11, on the other hand, aims at minimal costs, maximum availability and more effective use of rare blood types. They argue that for generalization of their results, the scenarios might need modification as there are differences in the blood supply system between countries. After all, they modeled the blood supply chain as they observe it in Finland. Nevertheless, they believe their attempt to improve the supply chain management of blood by means of simulation is a useful case study through its providing a basis for scenario building in other contexts.

\subsection{Queuing model}

Nine papers rely on the method of queuing theory and Markov chains in their approach to blood problems. Seven of these papers mention Markov chain modeling, sometimes used together with other methods.

Brodheim et al. (13), for example, combine Markov chain modeling with statistical analysis. They developed a model that is able to translate the demand for and usage of blood into availability and utilization as functions of the regional blood center's blood distribution policy and the hospital blood 
bank's blood stocking policy. The aim of their research was to derive regional allocation strategies with desirable properties regarding availability and utilization. They distinguish between retention units and rotation units. Rotation units are those that can be returned to the regional blood center when they are in excess of a predefined desired inventory level at the end of a period. These units can be redistributed by the regional blood center as retention units, in that way avoiding spoilage by outdating. The retention units, on the other hand, remain permanently at the hospital blood bank until they are transfused or outdated. Retention units are generally a couple of days older than rotation units when distributed to the hospital blood bank. The utilization rate is then determined by the number of retention units in inventory, since only these units are able to outdate at the hospital blood bank. Brodheim et al. use a finite-state Markov chain to model the number of retention units in inventory immediately after each delivery.

Pegels and Jelmert (24) evaluate several issuing policies on their effect on the average inventory level and the average age of blood at transfusion. Their work is a theoretical application of Markov chain modeling. The issuing policies evaluated do not concern regular LIFO and FIFO, but rather focus on slightly modified versions of these policies. Both the 'modified LIFO policy' and the 'modified FIFO policy' are considered. These differ from the regular policies in the sense that, for example, with FIFO there is a higher probability that older blood will be issued rather than fresher blood.

\subsection{Stochastic dynamic programming (SDP)}

Van Dijk et al. (42) combine stochastic dynamic programming with simulation to develop a new approach towards the blood platelet inventory problem. Stochastic dynamic programming is a mathematical optimization technique for problems in which decisions are taken periodically (42). The units they work with are so-called 'PLT pools', which is the amount generally required for one patient. A PLT pool is normally derived from five buffy coats. A buffy coat is a mixture of blood plasma and platelets that remains after the extraction of red blood cells. The platelets are extracted from these five different buffy coats and are subsequently pooled together into one PLT pool (41). The SDP method is used to minimize costs. Here they focus on the well known tradeoff between outdating and shortages. The SDP problem formulation is not much of a problem, however solving is. The size of the optimization problem is still a bottleneck, considering the power of a computer anno 2009. They deal with this issue by downsizing the problem before solving it. Furthermore, the optimal solutions from the SDP are likely to be complex and therefore impractical production strategies. The complexity emerges from the fact that the production decisions depend on the ages of the PLT pools, which the SDP formulation takes into consideration. After obtaining an optimal strategy for the downsized problem, they seek a simpler solution that is more useful in practice. A strategy based on a fixed - but for each day different - order-up-to level is sought by simulating the problem. They first check by simulation whether their optimal strategy resembles an order-up-to strategy, before simulating the strategy. Eventually, a best-fit order-up-to level is derived. Before upsizing the 
problem again, they first verify by simulation whether the order-up-to strategy performs sufficiently well compared to the optimal strategy. If it does, the problem and the obtained order-up-to levels are upscaled again. Eventually, to fine-tune the order-up-to levels, a simulation-based search algorithm (not explained in detail) is used.

Later, a remarkable fact arose from the practical implementation of the method in a Dutch regional blood bank (42). Distinguishing between blood groups and accounting for Rhesus factor proved to be unnecessary, because the amount of blood platelets needed was significantly less than could be produced from whole blood donations. They do mention that when the PLT demand fraction of the whole blood donations becomes higher, a distinction between blood groups could become necessary. Haijema et al. (41) extend the approach they developed in (42) to include irregular production breaks like Easter and Christmas. They find that the simple order-up-to rule remains nearly optimal, while during the breaks the outdating and shortages can still be kept less than $1 \%$. It is also found that the periods without production can be integrated into the periods with production.

We refer to section 2.5 for Blake’s (44) criticism of van Dijk et al. (42).

\subsection{Integer programming}

Hemmelmayr et al. (74) use integer programming in the problem of delivering blood products to Austrian Hospitals in a cost-effective manner. They investigate whether switching from the current vendee-managed inventory setup to a vender-managed inventory system would be beneficial. They also compare performance with an alternative solution approach based on a variable neighborhood search. Two alternative delivery strategies are investigated, not neglecting the desire for regularity in delivery patterns. The first strategy preserves the use of fixed routes and the concept of regions, but now uses integer programming techniques to decide on which days deliveries should best be made. In this approach, the set of hospitals is divided into four regions and the hospitals in each region are served by a single vehicle using a fixed route. The vehicle skips those hospitals that do not require a delivery. Fixed routes are often preferred because otherwise delivery routes must be recomputed each day. Given these fixed routes for each region, the integer programming model decides which hospitals to visit each day in such a way that there are no shortages at any hospital, while minimizing spoilage and delivery costs. They justify their choice of not taking inventory costs into account by pointing to the fact that hospitals prefer a high inventory to loss of life due to shortages.

The second strategy includes a more drastic change which combines flexible routing decisions with a focus on delivery regularity, implying repeating delivery patterns for each hospital. Now they view the problem as a periodic vehicle routing problem with tour length constraints and no capacity constraints. They developed a variable neighborhood search algorithm to solve this problem. This algorithm is a local search procedure which uses several neighborhoods (instead of one) which are systematically changed during search. This enables the algorithm to search increasingly larger neighborhoods of the current solution. 
Practical implementation was done by testing these two approaches on real data from the Austrian Red Cross. The two new approaches performed better than the basic approach, with the integer programming approach being more effective in more tightly constrained environments. The opposite is true for the variable neighborhood search approach.

They come to the overall conclusion that travel costs can be reduced significantly by using more sophisticated delivery strategies, which can lead to potential cost savings of approximately $30 \%$.

Hemmelmayr et al. (76) extend the approach of (74) to handle stochastic product usage. External sampling is used to convert the problem into a deterministic optimization problem.

Sahin et al. (75) develop integer programming models to solve location-allocation decision problems in the regionalization of blood services on the part of the Turkish Red Crescent Society. They use real data as input.

\subsection{Linear programming}

Prastacos (6) and Kendall (11)(88) use goal programming methods in their papers, which is an application of linear programming. Kendall (11) for example applies goal programming in the situation of blood rotation policies with multiple objectives. He emphasizes the merits of goal programming techniques by underlining characteristics such as low operating costs and the possibility of performing a sensitivity analysis by reordering objectives and changing goals. He also states that goal programming models are relatively easy to understand and verify compared to simulation models. The purpose of his goal programming model is to assist in the planning of collections, distribution and rotation. His model gives the decision maker the opportunity to set different goals which can be ranked according to different priority levels. That way, feasible rotation policies can be determined and one can observe the effects of these decisions.

As already mentioned before when talking about benchmarking methods, Pitocco and Sexton (18) formulate and solve their DEA model by means of linear programming.

\subsection{Statistical analysis}

Frankfurter et al. (67) utilize exponential smoothing techniques to forecast transfusions at the hospitals. Exponential smoothing is a forecasting technique which, as opposed to normal regression, is an auto-regressive method. This means that the dependent variable is forecasted using only previous values of that dependent variable, without any other explanatory variables. They also forecast outdates by using past collections as an explanatory variable. It has been found that a positive exponential function fits this relationship. He mentions how daily blood collections are forecast by a committee and then serve as input for an inventory projection model.

Melnyk et al. (51) work with survival analysis, which is a set of statistical techniques used to determine the quantitative impact of independent variables on a dependent variable. The dependent 
variable represents the time interval between events. It contains parametric, semi-parametric and nonparametric statistical techniques. They investigate data from the blood donation process using this technique to identify differences in processing time between different donor classes. They distinguish between three different groups of donors: regular, autologous and directed donors. Regular donors are those people who give blood to the general pool without restriction. These people form the largest group of donors and constitute the backbone of the system. The autologous donors, on the other hand, give blood for their own future use. These people are often older and/or handicapped, constituting a much smaller group. A third group is that of directed donors, which are people who give blood for a specific person or group of people (usually a family member). Donors are further broken down into first-time and repeat donors. Changes in this donor mix matter since they could affect the layout of the blood donation process. If all six classes are significantly different, then it might be worthwhile to develop a different layout for each class. They came to the conclusion that the difference between first-time and repeat donor had no impact on processing time distribution. They did find that it pays to have two separate stations at the health history stage of the donation process: one for regular and one for directed and autologous donors. For the other stages, there is no harm in treating the three donor groups as one.

The work of Melnyk et al. (51) is furthermore an illustration of the usefulness and applicability of survival analysis in operations management. This technique proves to be better than other statistical techniques when dealing with highly skewed, censored or longitudinal data.

Heddle et al. (15) use logistic regression techniques to determine the factors which affect red blood cell outdating. They fit linear regression models to red blood cell outdate data of hospital blood banks. Results of their statistical analysis prove a useful input for determining peer groups for benchmarking purposes.

Perera et al. (16) investigate which factors affect stock level and wastage in hospital blood banks. They use Student's t-test to analyse blood stock and wastage data. Data for the explanatory variables were collected via questionnaires. The questions concerned crossmatch reservation period, standard operating procedures for placing blood orders and method of calculating blood order, among other things.

Bosnes et al. (54) use a logistic regression model for the prediction of blood donor arrivals. The dependent variable is the response to scheduled donation appointments, while various factors are used as explanatory variables. These factors are chosen based on previous studies and include, for instance, donor age, previous donation pattern and previous short-time temporary deferrals.

Godin et al. (56) perform a logistic regression analysis to identify factors predicting repeated blood donation. They distinguish between experienced and new donors. They conclude that both donor groups demand a different promotion strategy in order to increase the level of repeated blood donation. 
Schreiber et al. (59) also use logistic regression techniques, this time to verify the hypothesis that first-time donors with a high donation frequency during the first year are more likely to become regular donors in the following years. The logistic regression analysis supports their hypothesis, which leads to the advice that it is beneficial to encourage first-time donors to donate again at regular times during their first year. That way, the chances are higher the donors will exhibit regular donation behavior in subsequent years.

Schreiber et al. (2) designed a questionnaire in which donors had to rate the importance of reasons not to donate on a five-point Likert scale. A categorical analysis of variance was used to compare the importance of these deterrents between first-time and repeat donors. It was also investigated whether there are differences between different ethnicities. The analysis revealed some differences between these groups, which are listed in their paper (2). The main conclusion of their study is that the overall most important reason not to donate was that of not having a convenient place to donate. They suggest that mobile collections and increased hours of operation could deal with this problem. Factors such as physical side effects, foreign travel and length of the donation process seemed to be less of a deterrent.

Carden and DelliFraine (81) use statistical analysis techniques to investigate the association between hospital satisfaction with blood suppliers and centralization of blood centers. Descriptive statistics such as frequencies, means and standard deviations are derived for each variable in their survey. They also perform a correlation analysis to measure linear associations between the variables. That way, variables that are closely correlated are identified and can be screened on their usability. Finally, a logistic regression helps determine the association between blood center centralization and each of the variables of hospital satisfaction. Logistic regression was preferred over discriminant analysis, even though both techniques are interchangeable in answering the research question. Logistic regression has the advantage over discriminant analysis that it has no normality assumptions about the distributions of the regressors. Since not all of the regressors in the data were normally distributed, logistic regression proves a more suitable method here. The result of their study is the detection of differences in hospital satisfaction between centralized and decentralized blood centers. Both types of system have advantages and disadvantages. It is up to the hospitals to consider which system is best for fulfilling their blood supply needs.

\subsection{Cost analysis}

We place papers that specialize in splitting up costs of operations in the cost analysis category. From the 98 papers, six papers were placed in this category.

Custer et al. (53) assess the cost of the blood supply. They distinguish between four categories in direct blood supply production costs: donor recruitment and selection, donation collection, donor 
screening and processing and donation distribution. They calculate total and unit costs by means of a spreadsheet program.

Rautonen (7) performs a cost analysis of the blood supply chain in Finland. The blood service costs of the Finnish Red Cross and the hospital costs are examined up to the point when the blood product is ready for transfusion. The analysis reveals that the material costs are only 25 percent of Finnish Red Cross blood service costs. Rautonen's suggestion is to cut down blood-related costs by improving processes both at the hospitals and the Finnish Red Cross. The study emphasizes the importance of cooperation between the two in order to achieve maximum results.

\subsection{Heuristics}

Hemmelmayr et al. (74) and (76) describe the use of a variable neighborhood search approach in the problem of delivering blood products to hospitals in Austria. For more information about these heuristics, we refer to the description of these papers in the section on integer programming problems.

\subsection{Mathematical proofs/derivations}

Kaspi and Perry (31) prove various lemmas and theorems in the field of inventory systems of perishable commodities. Other papers featuring mathematical proofs or derivations can be found in Jagannathan and Sen (52), Pierskalla and Roach (66), Prastacos (68) and (69).

\subsection{What-if scenario analysis}

We have included a category for scenario/impact analysis. Only three papers fit into this category. Davis et al. (20) discuss the impact of using high frequency radio frequency identification (RFID) tags to track blood products in blood centers. They deal with both process and technological perspectives. Technological issues such as readability, performance, temperature and biological effects of radio frequency energy on blood products are evaluated. Also, RFID system architecture design and standards are assessed. Davis et al. (20) conclude that it is perfectly feasible to apply radio frequency identification in the blood center process. The technology is safe to use in conjunction with the blood products reviewed (only red blood cells and blood platelets were included in this study). Productivity and quality improvements would render a payback period of four years, justifying the investment cost. Other scenario analyses can be found in Galloway et al. (36) and Hess (8).

\subsection{Custom spreadsheet method}

An example of these spreadsheet method papers can be observed in (9) where Erickson et al. develop a computer spreadsheet-based disaster prediction model to manage the use of frozen RBCs by testing various emergency scenarios. They confirmed the hypothesis that a frozen RBC inventory can only serve as a short-term bridge-over supply in the event of an emergency when the supply coming from 
the blood center is cut off. In the event of extreme and/or prolonged disasters, the frozen RBC reserve proves an inadequate source to meet a huge transfusion demand. Instead, they defend the use of an expensive frozen blood supply as a valuable part of a comprehensive disaster management plan.

Custer et al. (53) assess the cost of the blood supply. They calculate total and unit costs by means of the spreadsheet program Excel.

\subsection{Trends in solution method}

Figure 3 shows the number of publications over time for each type of solution method. From this graph one can conclude that, during the last decade, papers involving 'soft computational' approaches (like simulation, statistical analysis and evaluation/best practices) outnumber publications involving 'hard computational' approaches (including linear programming, integer programming and stochastic dynamic programming). The number of papers presenting an integer programming approach was equal to the number of papers describing a custom spreadsheet approach between 2006 to 2010. Only one paper written after 1980 contains a mathematical proof. These observations suggest that nowadays researchers from various fields (health care managers, business economists, computation scientists ,etc.) study blood supply management problems, while in the seventies (only) researchers with a strong mathematical background (mathematicians, operations researchers, etc.) studied this subject. Modern papers often present a user-friendly approach (e.g., discrete event simulation software) which can be used directly by health care managers to evaluate a limited number of scenarios rather than identifying (sub)optimal policies from a wide range of candidate solutions. Finally, recent research tends to emphasize the multi-disciplinary aspect of blood product supply chain management. This translates into the application of methodologies from different fields (econometrics, database management, operations management, operations research, etc.) rather than developing a sophisticated linear (integer) programming or dynamic programming model without implementation in a decision support system. 


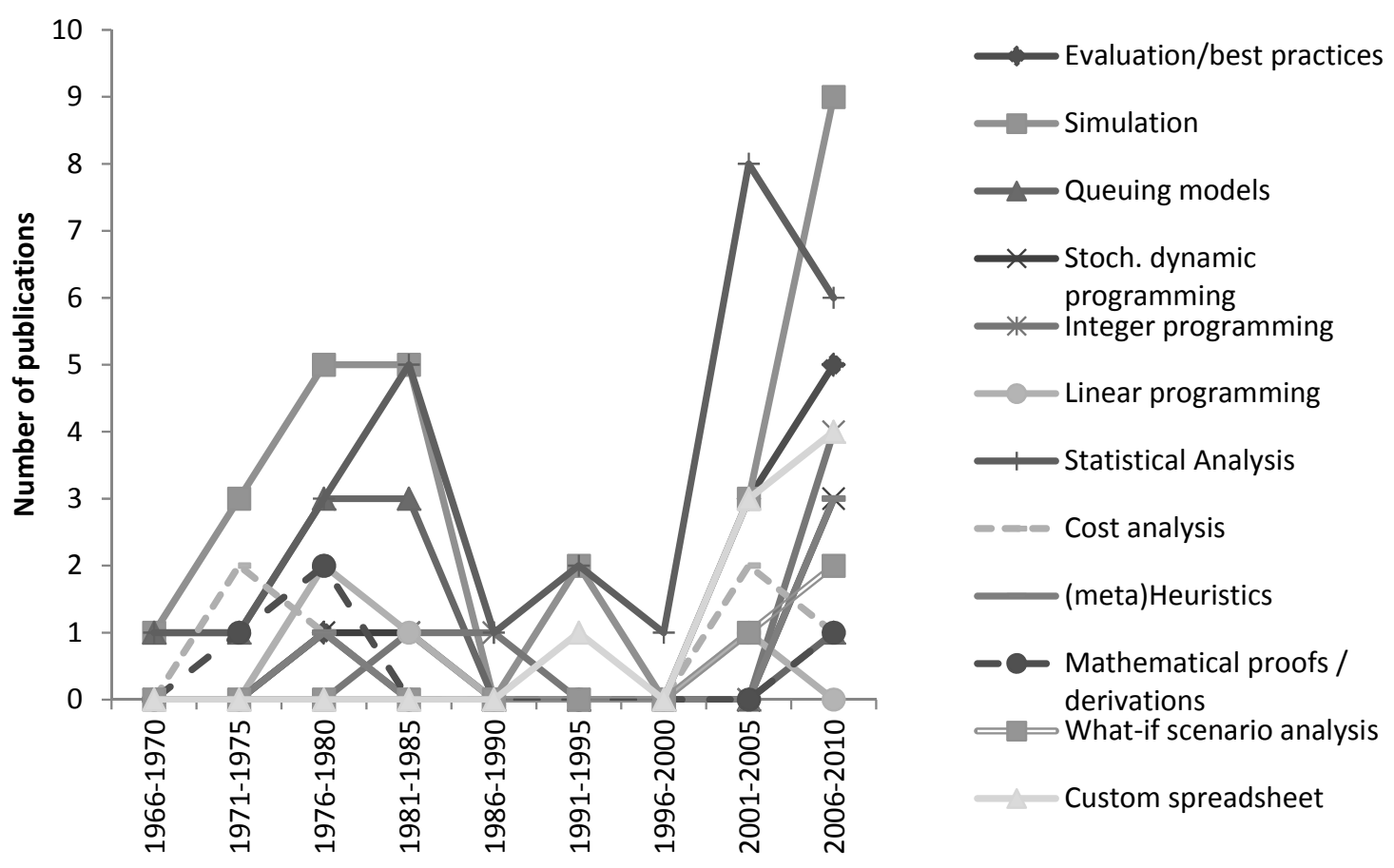

Figure 3: Trends in solution method

\section{Hierarchical level}

The literature can be classified at three different hierarchical levels in the problem field: individual hospital level, regional blood center level and supply chain level. Some papers apply to several of these levels, while others focus on only one specific level. The individual hospital level includes hospital blood blanks and policy decisions relevant at this level. The regional blood center level concerns, among other things, redistribution policies between hospitals. Papers dealing with the issue of whether a centralized system outperforms a decentralized system are also included at this level. We have included the supply chain level because some papers specifically aim at improving the whole supply chain of blood, instead of focusing on one part of the chain. The supply chain level also includes papers that concern interregional policy decisions. Table 3 lists the papers according to hierarchical level.

\subsection{The individual hospital level}

Out of the 98 papers, 37 concern the individual hospital level. Dumas and Rabinowitz(12) discuss policies for reducing blood wastage in hospital blood banks. Heddle et al. (15) provide an approach to establishing benchmarking targets for red blood cell outdates at hospital blood banks. They analyzed 156 hospitals to identify factors that were responsible for red blood cell outdating. These results were then used to categorize the hospitals into groupings depending on the factors that affected wastage. For each group, a benchmarking target can then be established. Similarly, Perera et al.(16) examine 
the factors affecting stock level and wastage at hospital blood banks in the United Kingdom. Another study of the same kind can be found in Pink et al. (84). They also try to determine the factors which cause the outdating of donor blood. For this purpose, they reviewed the inventory management of Sydney's public hospital blood banks. Brodheim et al. (25) determined what inventory levels hospital blood banks should set. Vrat and Khan (79) simulate the inventory system in a hospital blood bank. Elston and Pickrel (98) provide a statistical approach to ordering and usage policies for a hospital blood bank, while Jennings (61) analyses whole blood inventory control policies at hospital blood banks. Carden and DelliFraine (81) examine the relationship between blood center structure and hospital patient satisfaction. Since they consider the advantages and disadvantages of both centralized and decentralized blood centers, this paper has also determined to concern itself with the regional blood center level. Rabinowitz (82) uses computer simulation to evaluate blood bank inventory policies, with data from the New York Hospital as input. Another simulation study is that of Friedman et al. (28), who derive a blood ordering strategy for hospital blood banks. Pegels et al. (32) performed simulation runs to examine the effect of several policies on the hospital's blood inventory behavior. One of the policies was the freezing of red blood cells, which led to a more stable operation of the hospital blood bank while outdating remained constant. As all the policies tested require changes in the management of regional blood services, this paper can also be classified at the regional blood center level.

Table 3 - hierarchical level

\begin{tabular}{ll}
\hline individual hospital level & $(91)(61)(90)(6)(1)(65)(3)(85)(37)(95)(9)(10)(15)(16)(81)(32)(4$ \\
& $7)(35)(92)(38)(97)(79)(28)(45)(25)(26)(84)(42)(41)(12)(44)(82)$ \\
& $(52)(66)(39)(40)(72)$ \\
& $(30)(89)(88)(90)(78)(94)(74)(6)(87)(1)(65)(76)(3)(11)(34)(68)($ \\
& $69)(13)(86)(85)(48)(10)(20)(81)(62)(32)(73)(67)(77)(51)(54)(4$ \\
& $2)(41)(44)(83)(29)(53)(17)(39)(50)(40)(71)(96)$ \\
& $(43)(7)(1)(3)(4)(18)(21)(63)(36)(14)(75)(83)(39)$ \\
regional blood center level & $(93)(46)(23)(22)(49)(80)(55)(56)(8)(57)(58)(59)(2)(60)(27)(5)($ \\
supply chain level & $64)(70)(33)(24)(31)(19)$ \\
not specified/unclear &
\end{tabular}

\subsection{Regional blood center level}

The largest set of papers applies to this hierarchical level. Out of the 98 papers, 43 papers bear upon the regional blood center level. Denesiuk et al. (30) discuss a redistribution system for near-outdate red blood cells. The idea is to transport units that are about to outdate from a low-usage hospital to a high-usage hospital. At their new destination, the units would have a greater chance of being used before they outdate, thus reducing the overall discard rate in the region. The study reports on the 
implementation of such a system in Canada, and pays attention to implementation issues such as the type and cost of the packing material used for transportation. Cumming et al. (29) refer to a collections planning model for regional blood suppliers. The purpose is to assist regional blood suppliers in flattening out seasonal imbalances between the supply of and demand for blood. Implementation of the planning model would lead to an improvement in the scheduling of blood collection operations. Gregor et al. (78) evaluate the inventory and transportation policies of a regional blood distribution system. A simulation model is used to analyze the costs and effects of several operational policies, such as changing the number of delivery vehicles and increasing the amount of blood available. Kahn et al. (73) discuss the impact of converting to an 'all frozen blood' system in a large regional blood center. Their conclusion is that the implementation of such a system would lead to an increase in the average cost of a unit of blood of 80 percent. Prastacos and Brodheim (34) describe the so-called 'Programmed Blood Distribution System', which is a decision support system for regional blood management. The system contains separate modules for policy selection, distribution scheduling and control procedure. This system has been implemented in the region of Long Island, New York. Frankfurter et al. (67) report forecasting models, developed for the Albany, New York regional system. A short-term computerized blood inventory level forecast system is dealt with. This system intends to alert regional blood center management to the short-term inventory level of blood supplies. That way, corrective action can be taken by either reducing or increasing blood collections. Prastacos (68) analyzes allocation policies of a perishable product from a regional center to different locations in the region. Although this study does not only apply to blood but also to other perishable products such as food and medical drugs, an example of application in blood management is presented in this work.

Similar studies can be found in Prastacos (69) and Federgruen (87). Kendall (88) emphasizes the importance of annual planning of the operation of a regional blood system, instead of only focusing on daily inventory control. An annual plan to attain the goals of a blood service organization is suggested. The model formulated in this study should help regional blood administrators in determining the magnitude of the blood collection effort and the size of the regional blood inventory. An application of the procedure in a blood region of the USA is examined.

\subsection{Supply chain level}

We have included this hierarchical level to classify the papers that specifically focus on the entire supply chain. Papers that are directed towards blood program management (interregional) are also included at this level. The literature review of Pierskalla et al. (3) focuses on supply chain management of blood banks. Their study includes an outline of the blood banking supply chain and a discussion of several tactical and operational issues faced by this chain. Questions such as which blood banking functions should be performed, which location should be used for these functions, the number of community blood centers that should be in a region, where these community blood centers 
should be located and which donor areas and transfusion services should be assigned to which community blood center, are addressed in this review. Other problems addressed in their review are the following: the collection of blood, producing multiple products, setting and controlling inventory levels, allocating blood to hospitals, delivery to multiple sites, issuing policies and crossmatching policies. Katsaliaki (1) evaluates the performance of the entire blood supply chain in the UK. The aim of the study is to discover policies that turn out to produce a more cost-effective management of the supply chain, while at the same time safety is increased. Kamp et al. (14) investigate the availability of red blood cells in the German supply chain during an influenza pandemic. Their main conclusion is that pandemic preparedness can only be established when there is detailed knowledge about the fraction of transfusions that cannot be postponed. The definition of criteria for prioritization of transfusions is suggested to deal with the danger of an influenza pandemic. Fontaine et al. (43) aim at improving the platelet supply chain by emphasizing the importance of narrow collaboration between blood centers and hospital transfusion services. They suggest a multidisciplinary approach, with external aid from experts in supply chain management. The included case study shows the benefit of combining forces by presenting a reduction in the PLT outdate rate, which allows for considerable cost reductions. Rytilä and Spens (4) build a simulation model of the blood supply system in Finland. The steps in the simulation process as well as the results are described. Only some initial results are reported in the paper since the project was still ongoing at the time of writing.

\subsection{Trends in hierarchical level}

Figure 4 depicts the number of publications over time for each hierarchical level of blood supply chain management. The number of papers on the individual hospital level and regional blood center level follow the same trend as the general number of papers (see Figure 1), while the supply chain level was hardly studied before 2000 (only 1 paper). During the last decade, however, the number of publications on the supply chain level have catched up with the individual hospital and regional level. 


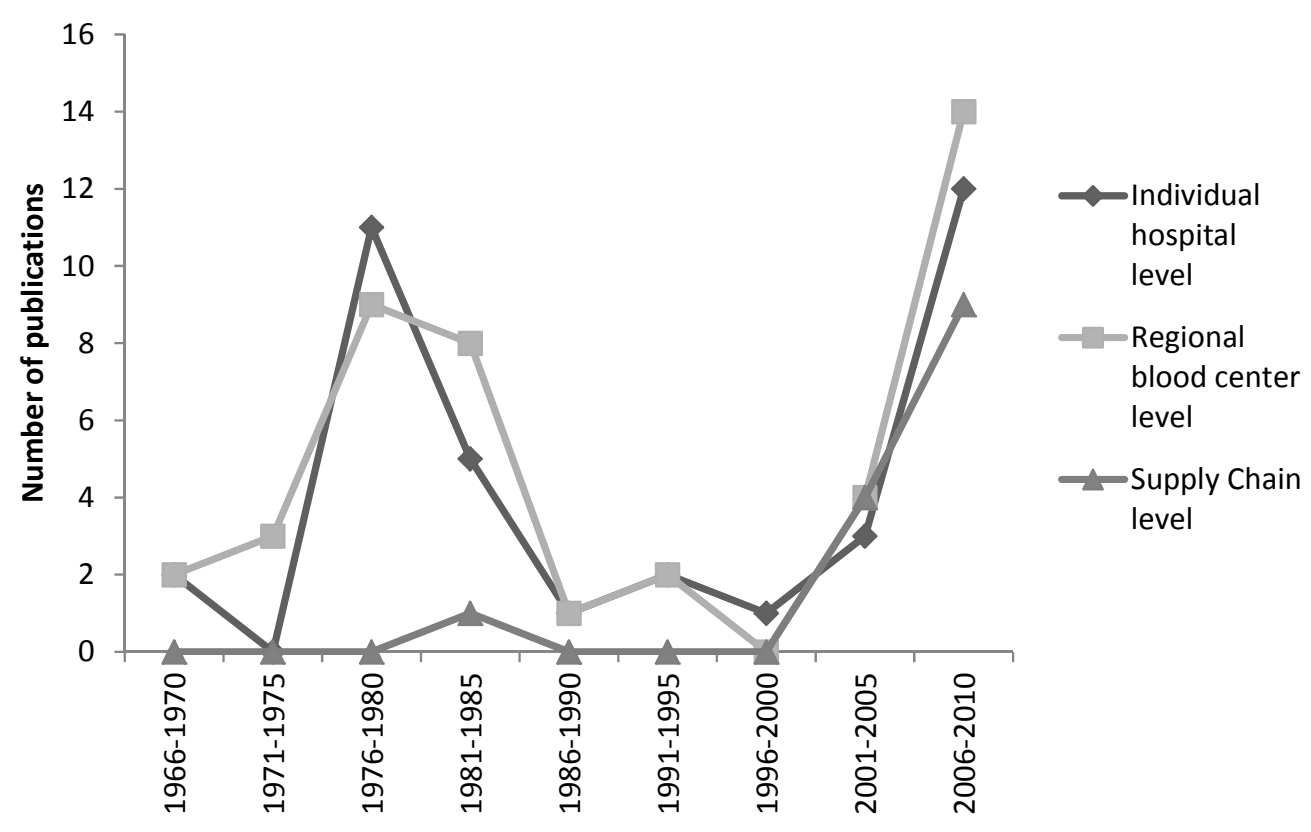

Figure 4: Trends in hierarchical level

\section{Type of problem}

Supply chain management of blood products consists of various subproblems. We distinguish between inbound and outbound problems. Inbound problems comprise both inventory problems and problems dealing with planning for collections. Outbound problems consider problems regarding distribution scheduling as well as problems related to supply.

\subsection{Inbound problems}

We encountered two types of ordering policies within inventory management, with the majority focusing on fixed order intervals (order-up-to models).We believe Katsaliaki (1) mentions a min-max model in her simulation study, though the difference from fixed order interval models is not always clear in the literature. Min-max models are a combination of models with ordering points and models with fixed order intervals. Since Katsaliaki(1) draws a distinction between routine (prescheduled) deliveries and emergency (ad hoc) deliveries, the model can be labeled as a min-max model. Fixed order interval inventory models can be found in Sirelson and Brodheim(45), van Dijk et al.(42), Prastacos(6), Haijema et al.(41), Jennings(65) and Pierskalla (3).

Inventory allocation problems concern the efficient allocation of inventory in the supply chain. Sources dealing with the issue of centralized structures, as opposed to decentralized structures, are also included in this category. Carden and Dellifraine(81), for instance, investigate the advantages and 
disadvantages of both centralized and decentralized blood centers. They conclude that there are significant differences regarding hospital customer satisfaction. Centralized blood centers proved to be more successful in meeting the overall supply needs of hospitals, while decentralized blood centers appeared to charge lower prices and offer products that are more adapted to local market needs.

Federgruen et al.(87) discuss an allocation model for perishable products, distributed from a regional center to a given set of locations with random demands. The paper actually deals with a combined problem, since it also considers the problem of distribution scheduling. Though their focus is not on blood products specifically, applications using blood products are possible since blood is a perishable product.

Cross-matching policies and issuing policies are also included within inventory management. A crossmatching policy reduces to an issuing policy when all cross-matched units are actually used. Since this is only the case for general perishable products and not for blood products, a distinction between the two policies is necessary (6). Dumas and Rabinowitz (12) attempt to reduce blood wastage by an alternative cross-matching policy. Instead of the conventional single cross-matching, they emphasize the merits of double cross-matching. In that case, a single unit of blood is reserved for two potential users instead of one, while ensuring blood is available for both when it is needed. This policy increases the probability that the blood unit will be used during the reservation period, which has the advantage of having fewer unused units reserved that are unavailable to other patients. Another example is the work of Jagannathan and Sen (52), which is dedicated to the storing of cross-matched blood. Issuing policies are discussed in detail in Pierskalla and Roach (66), who derive optimal issuing policies for some particular classes of perishable inventory problems. An example about the issuing of whole blood from a blood bank is included to accompany their theory. Another discussion of issuing policies can, for instance, be found in Prastacos (6).

The papers that concern inventory management in yet other fields than those defined in Table 4 are placed in the leftover category 'other'. This category includes studies about efficiency and best practices, emergency management plans, demand forecasting, computer-based information systems, extending the shelf life of blood components and other topics that relate (in)directly to blood supply chain management. Katsaliaki (1), for instance, is placed in this category, because this paper also discusses the benefits of a computer-based information system, even though this paper is already classified in different subcategories of inventory management (min-max inventory model, crossmatching and issuing policies).

A separate category was reserved for those papers that deal with planning for collections, which we also consider an inbound problem. The model of Cumming et al. (29), for instance, focuses on the planning of blood collections by scheduling and rescheduling bloodmobile operations to achieve the desired targets. Pegels et al.(32) discuss various blood service policy changes, which include the use of a scheduling algorithm to schedule visits to organizations. A simulation study of donor scheduling 
systems for the American Red Cross can be found in Michaels et al.(64). Table 4 lists the papers according to inbound problems.

Table 4 - Inbound problems

\begin{tabular}{ll}
\hline $\begin{array}{l}\text { inventory management } \\
\text { fixed order interval }\end{array}$ & $(45)(42)(6)(41)(65)(3)(40)(72)$ \\
min-max inventory model & $(1)$ \\
inventory allocation & $(43)(81)(5)(78)(77)(6)(87)(75)(3)(34)(68)(69)(39)(71)$ \\
cross-matching policies & $(37)(80)(16)(90)(35)(92)(38)(26)(6)(1)(12)(4)(82)(3)(52)$ \\
& $(39)(71)$ \\
& $(43)(32)(5)(24)(42)(6)(1)(3)(17)(66)(71)$ \\
issuing policies & $(22)(85)(86)(48)(80)(9)(10)(15)(16)(43)(18)(7)(20)(8)(21)(61)($ \\
other & $62)(63)(27)(32)(73)(67)(88)(47)(90)(97)(78)(79)(28)(70)(33)(1$ \\
& $4)(25)(26)(84)(31)(42)(6)(1)(12)(44)(4)(83)(46)(23)(3)(52)(17)($ \\
& $95)(36)$
\end{tabular}

planning for collections

$(43)(32)(64)(51)(54)(6)(29)(50)$

\subsection{Outbound problems}

The supply category consists of papers dealing with how to maintain or increase the supply of donor blood. Assuming a non-decreasing trend in the demand for blood products, this category is indirectly relevant to our review. Madden et al.(19), for instance, investigate the impact of using a specific red blood cell collection technology on the availability of the product. More specifically, they discover that using a double red blood cell collection device leads to substantial gains in availability compared to conventional whole blood donation. It is also confirmed that the net gain in quantity of red blood cells in the supply is sustained under various policies. The authors are not sure about the economics of the collection system, though. Schreiber et al. (59) discovered that first year donation patterns predict long term commitment for first-time donors. This is relevant in the sense of determining strategies to establish regular donation behavior in the donor reserve. A similar study can be found in Chung et al. (58). Another study by Schreiber et al. (2) attempts to identify factors that prevent donors from donating, making it possible for the blood centers to address these issues.

Hemmelmayr et al. (74) deal with problems of delivering blood products to hospitals in Austria. They examine the potential benefits of a vendor-managed inventory system compared to the vendeemanaged inventory system currently in use. In addition to the system in use with fixed routes, two alternative solution approaches with a more flexible routing system are formulated to investigate whether a reduction in delivery costs is possible. An extension of this study to deal with stochastic 
product usage can be found in Hemmelmayr et al. (76). Kendall and Lee (11) formulate rotation policies that optimize the redistribution of blood between hospital blood banks. Redistribution generally occurs from hospitals with a lower probability of transfusion to hospitals with a higher probability. They indicate the increase in performance of multiple criteria that can be achieved by optimizing this process. Brodheim and Prastacos (13) discuss the Long Island blood distribution system as a prototype for a regional blood center and the hospital blood banks that it services. The prototype comprises a Programmed Blood Distribution System (PBDS) model and strategy which would be generally applicable. The PBDS schedules deliveries depending on statistical estimates of the needs of each hospital. Actual requirements are also monitored to adjust deliveries when necessary. Table 5 lists the papers dealing with outbound problems.

Table 5 - Outbound problems

\begin{tabular}{ll}
\hline supply & $(22)(49)(18)(55)(56)(57)(58)(59)(2)(60)(62)(63)(53)(19)(39)$ \\
& $(30)(91)(89)(43)(7)(61)(88)(90)(78)(93)(94)(74)(6)(87)(1)(65)($ \\
distribution scheduling & $46)(23)(76)(3)(11)(34)(68)(69)(13)(86)(39)(96)$ \\
\hline
\end{tabular}

\subsection{Trends in type of problem}

Figure 5 represents the number of publications on inbound and outbound problems over time. During the last decade, there is a steep increase in the number of publications studying inbound problems. From Figure 6 we conclude that inventory management problems represent the main category within the inbound problems. With respect to outbound problems, we see a recent climb in papers describing distribution scheduling problems. Figure 7 shows the trends within the inventory management problems. During the last ten years there is a remarkable rise in papers on 'other inventory management problems'. This last graph suggests that new research will continue to focus on developing new inventory policies rather than adopting classic inventory models like Fixed order interval policies or Min-Max inventory models for blood products. 


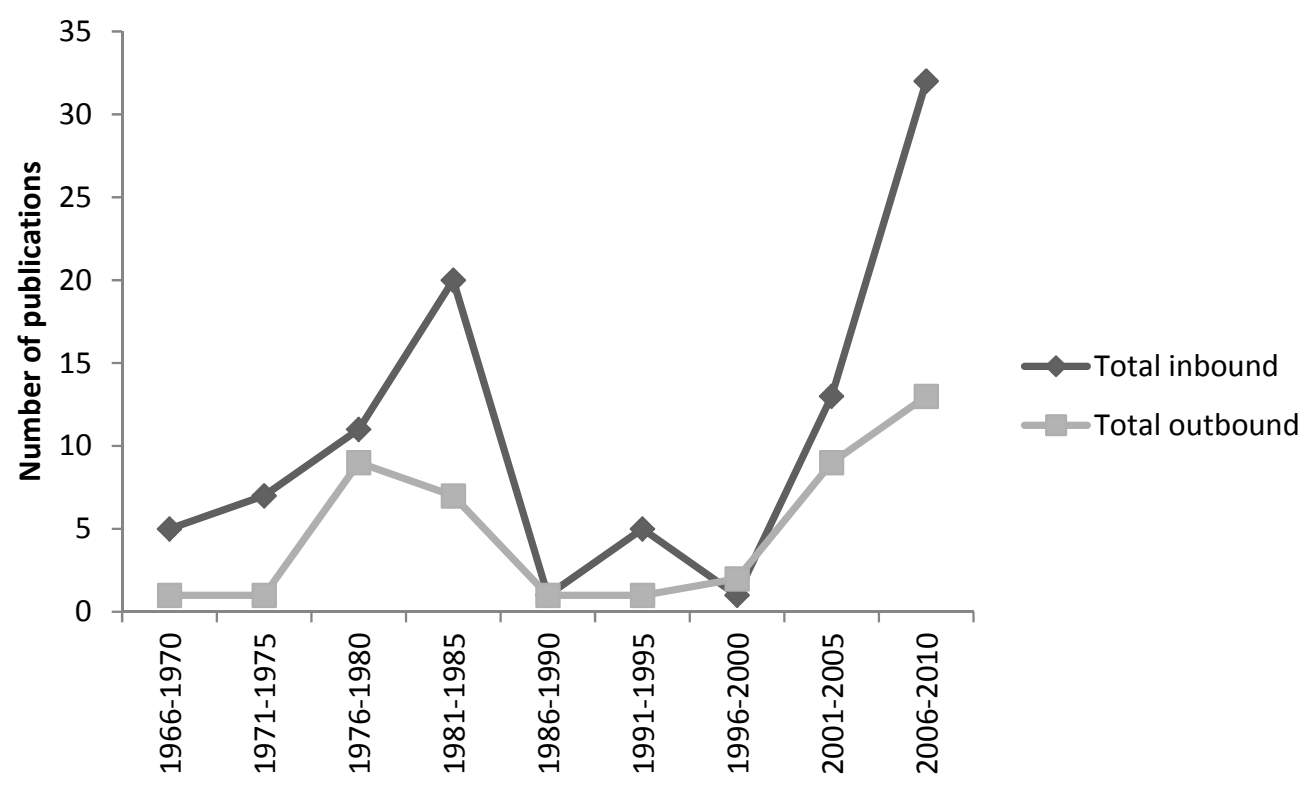

Figure 5: Trends in inbound versus outbound problems

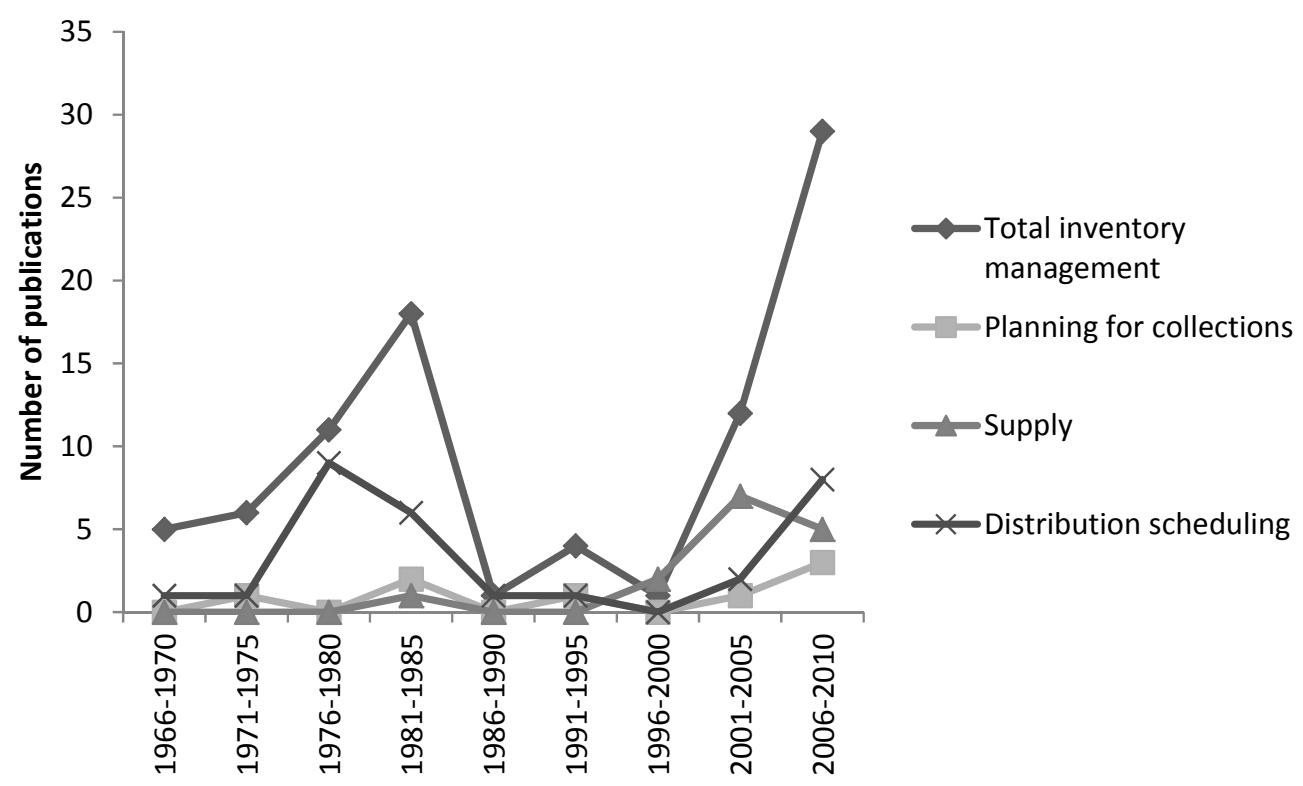

Figure 6: Trends in the main type of problem categories 


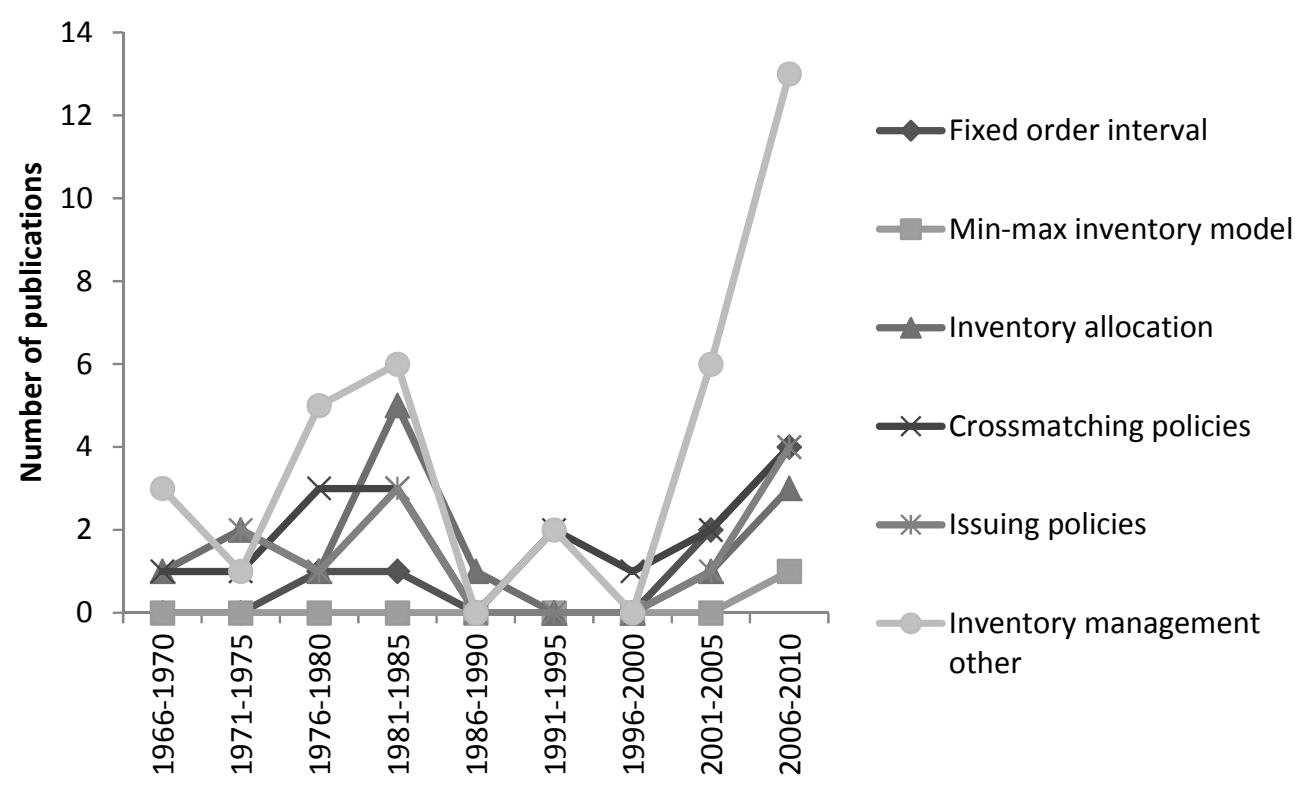

Figure 7: Trends in type of inventory problems

\section{Type of approach}

We distinguish between a stochastic and deterministic approach to the problem. For a lot of papers, classification according to this criterion is irrelevant. For instance, papers dealing with forecasting are always stochastic in view of the nature of the problem. Another example where this distinction is not relevant is studies dealing with benchmarking. We only made this distinction for those papers where different approaches are possible. Papers where simulation methods are used are placed under a stochastic approach. The most obvious example of a different approach can be seen in the two papers written by Hemmelmayr et al. As mentioned before, Hemmelmayr et al.(74) discuss delivery strategies for blood products. The investigation is set in a deterministic setting, but later extended in Hemmelmayr et al. (76) to deal with stochastic product usage. Remarkably, only seven papers are set in a deterministic setting, whereas 42 papers are set in a stochastic setting. This result is understandable, since stochastic settings resemble the practical environment more closely (74). Table 6 lists the papers according to type of approach. 
Table 6 - Type of approach

\begin{tabular}{ll}
\hline stochastic & $(45)(51)(14)(54)(24)(25)(26)(84)(31)(42)(6)(87)(41)(1)(75)(12)(44)(4)(19)(82)(8$ \\
& $3)(29)(65)(46)(53)(23)(76)(3)(11)(52)(17)(66)(68)(69)(13)(93)(94)(39)$ \\
& $(40)(71)(72)(96)$ \\
deterministic & $(74)(52)(66)(34)(93)(94)(50)$ \\
irrelevant/unclear & $(22)(30)(85)(86)(48)(49)(37)(91)(95)(80)(89)(9)(10)(15)(16)(43)(18)(55)(7)(56)($ \\
& $20)(8)(57)(58)(59)(2)(60)(21)(61)(81)(62)(63)(27)(32)(73)(67)(88)(47)(90)(35)(3$ \\
& $6)(92)(38)(97)(5)(78)(79)(64)(28)(70)(33)(77)$
\end{tabular}

Figure 8: Trends in type of approach identifies the trends in type of approach. The papers involving a stochastic setting have always outnumbered the papers involving a deterministic setting. During the last decade, the difference has only become larger. This trend suggests that future research will continue to study a stochastic setting.

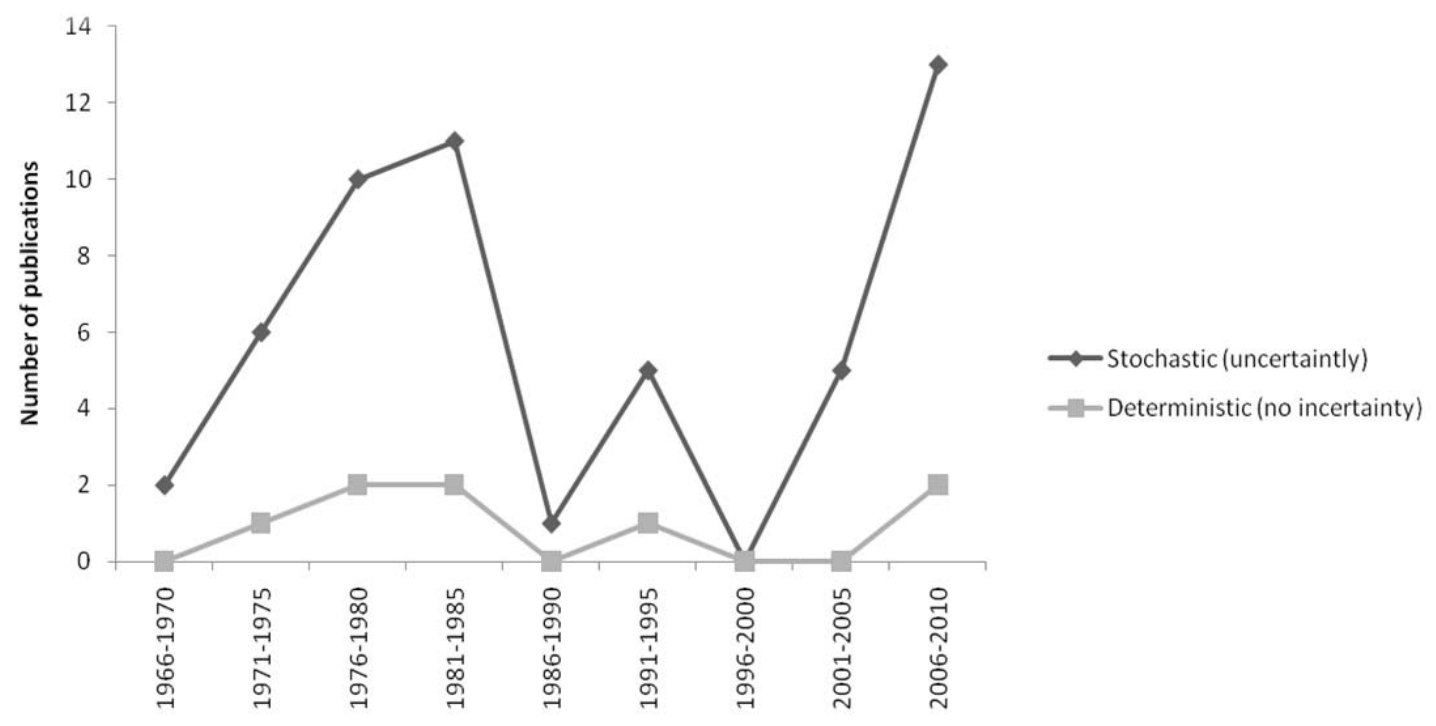

Figure 8: Trends in type of approach

\section{Exact versus heuristic}

Papers in which optimization problems occur can be classified according to this criterion. It appears that a lot of papers rely on heuristic approaches to solving problems of a realistic size. Simulation studies are also placed under heuristic approaches, since they cannot lead to an exact optimal solution. Other papers that use linear programming, integer programming or that contain mathematical derivations can be assumed to be exact procedures, except for those papers that solved the exact formulation by heuristic procedures. Heuristic procedures can be found, for instance, in the two 
papers of Hemmelmayr et al. (76) (74), which describe the use of a variable neighborhood search algorithm as a heuristic to solve a periodic vehicle routing problem. Another example of heuristic solution approaches can be found in van Dijk et al. (42). The problem is formulated in a mathematical form, the solving of which leads to the identification of an optimal production policy. Up to this point the paper concerns exact solution approaches. The study, however, continues with the computation of more simple, but only nearly optimal, order-up-to rules for production. This is an example of a paper that can be placed in both categories. Examples of pure exact solution approaches can, for instance, be found in Kendall (11), who uses linear programming methods to optimize blood rotation policies considering multiple objectives.

For part of the papers, the classification according to this criterion was irrelevant or unclear due to lack of information. These papers are listed in Table 7.

Table 7 - Exact versus heuristic

\begin{tabular}{ll}
\hline exact & $(3)(42)(5)(74)(6)(11)(52)(17)(77)(80)(66)(34)(68)(69)(87)(89)(1$ \\
& $3)(39)(50)(72)$ \\
& $(42)(5)(74)(6)(87)(41)(1)(75)(12)(44)(4)(19)(78)(79)(82)(64)(28$ \\
& \\
heuristic & $(83)(29)(65)(46)(70)(33)(53)(23)(76)(39)(71)(96)$ \\
& \\
irrelevant/unclear & $(9)(10)(51)(14)(15)(16)(43)(18)(54)(55)(7)(56)(20)(8)(57)(58)(5$ \\
& $9)(2)(60)(21)(22)(61)(81)(62)(63)(24)(25)(26)(45)(27)(84)(30)($ \\
& $31)(32)(73)(85)(86)(67)(88)(47)(90)(48)(49)(35)(36)(37)(91)(92$ \\
& $(93)(38)(97)(94)(95)(40)$
\end{tabular}

Figure 9 compares the evolution in the number of papers describing exact approaches with the evolution in the number of papers describing heuristic approaches. In the eighties, publications on exact approaches slightly outnumber publications involving heuristic approaches, while in the period 2005-2010 heuristic methodologies are more popular than exact methodologies. The difference is, however, too small to call it a trend. Consequently, it is very difficult to forecast which of both approaches will receive the most attention in the (near) future. 


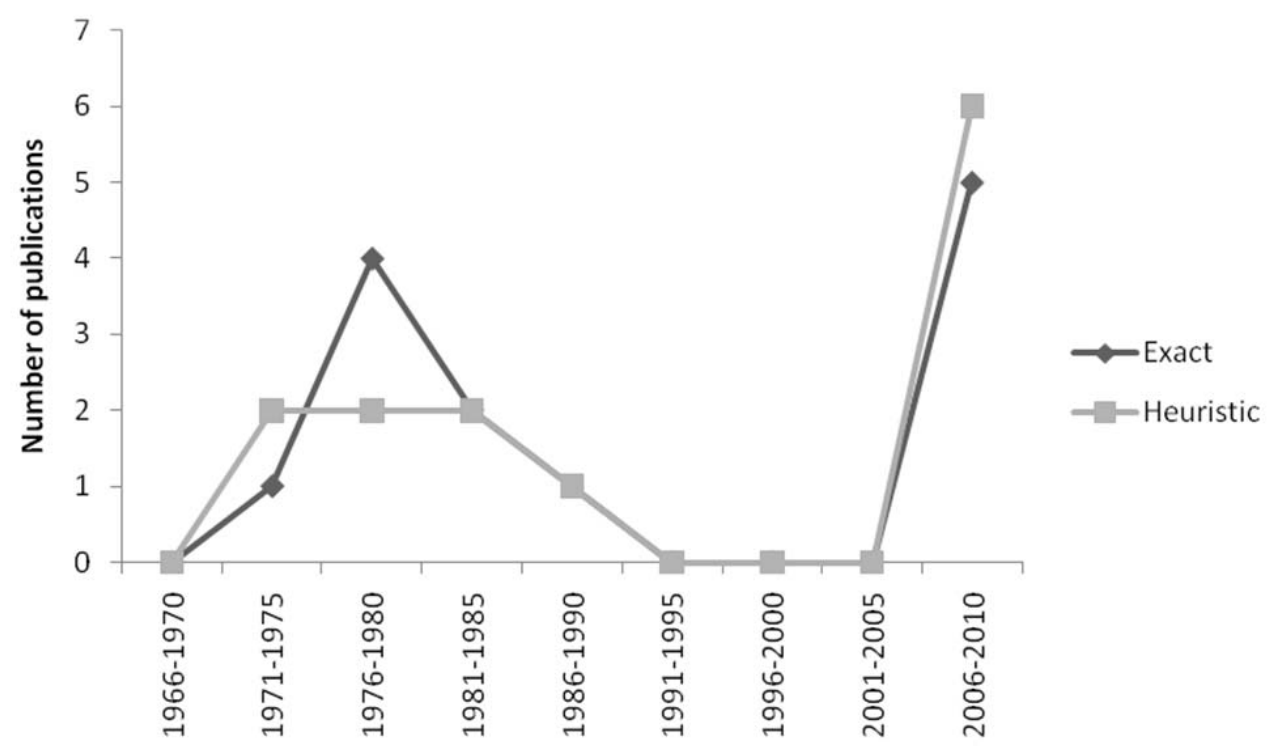

Figure 9: Trends in exact versus heuristic approaches

\section{Performance measures}

In the course of our research, we have encountered a lot of performance measures, some more apparent than others. In Table 8 a meaningful aggregation of measures is presented. The two most common categories of performance measures are those considering the number of outdated units and the number of units short of demand. Of the 98 papers observed in this review, 59 papers relate to the measure of outdates. Discussions focusing on shortages and related measures can be found in 38 papers. The aggregated measure of availability, containing also stock level, service level and days of supply, is closely related to shortages, since minimizing shortages automatically has a positive influence on stock level. Stock level occurs as a performance measure in 24 papers. The measure of the number of deliveries or transportation costs is particularly relevant for papers dealing with distribution scheduling. We encountered ten papers that use this measure. A less tangible performance criterion is the measure of safety and quality. Papers concerned about the age of blood units at the time of transfusion also fit this measure. The measures of processing times of donors in the donation process, number of arrivals to appointment and donation frequency are only relevant for papers dealing with supply problems. Nine papers use this type of measure. We have included a leftover category for all other measures that are of secondary importance, considering the type of problems in this review. Some papers mention operating costs and other financial measures, but these measures were encountered less often that the others and give less insight into the origin of costs. All papers containing other measures than the ones mentioned are placed in this leftover category, as well as papers lacking (clear) performance measures. Pierskalla et al. (3), for instance, is included in this leftover category, because this paper also mentions performance measures such as operating costs and man hours, even though this paper is already placed in other categories of performance measures 
(outdates category, shortages category and deliveries category). Table 8 lists the papers according to performance measures.

Table 8 - Performance measures

\begin{tabular}{|c|c|}
\hline outdates/outdate rate/wastage & $\begin{array}{l}(3)(97)(95)(44)(91)(13)(23)(89)(86)(21)(80)(70)(90)(47)(20)( \\
30)(92)(12)(87)(43)(67)(49)(28)(37)(78)(41)(15)(76)(8)(52)(6 \\
1)(65)(31)(1)(83)(46)(11)(22)(17)(48)(5)(35)(38)(32)(16)(66)( \\
84)(6)(34)(68)(69)(82)(4)(77)(45)(42)(79)(39)(40)(71)(72)\end{array}$ \\
\hline shortages/shortage rate/backorders & $\begin{array}{l}(3)(44)(13)(23)(25)(80)(70)(90)(33)(9)(87)(67)(28)(78)(41)(8) \\
(52)(61)(65)(14)(31)(1)(83)(11)(17)(5)(24)(32)(66)(6)(34)(68) \\
(69)(4)(45)(42)(79)(39)(71)(72)\end{array}$ \\
\hline deliveries/transportation costs & $(90)(87)(76)(74)(1)(3)(6)(75)(39)(50)(96)$ \\
\hline $\begin{array}{l}\text { availability/stock level/service } \\
\text { level/days of supply }\end{array}$ & $\begin{array}{l}(23)(89)(86)(90)(47)(29)(30)(28)(36)(62)(31)(83)(46)(22)(17) \\
(48)(19)(24)(32)(26)(16)(4)(63)(39)\end{array}$ \\
\hline $\begin{array}{l}\text { safety/age blood at } \\
\text { transfusion/quality }\end{array}$ & $(1)(53)(92)(43)(49)(28)(62)(8)(83)(11)(24)(32)(66)(63)(39)$ \\
\hline $\begin{array}{l}\text { processing times (donors)/arrivals to } \\
\text { appointment/donation frequency }\end{array}$ & $(54)(58)(62)(56)(57)(51)(64)(2)(59)$ \\
\hline other/unclear/irrelevant & $\begin{array}{l}(81)(27)(47)(33)(53)(55)(20)(30)(67)(49)(37)(8)(85)(93)(94)( \\
73)(31)(83)(11)(22)(88)(17)(19)(38)(32)(10)(3)(18)(7)(75)(60 \\
)\end{array}$ \\
\hline
\end{tabular}

Figure 10 depicts the trends in objective. Most objectives follow a similar trend, which makes it difficult to forecast which of these objectives will be most studied in the (near) future. We do observe, however, a vast increase in papers optimizing transportation and delivery during the last five years. Almost all publications on donor related objectives and many of the papers on safety and quality are published during the last decade. Nevertheless, these modern objectives are still studied less than the traditional objectives (outdates, shortages, availabilities and transportation issues). 


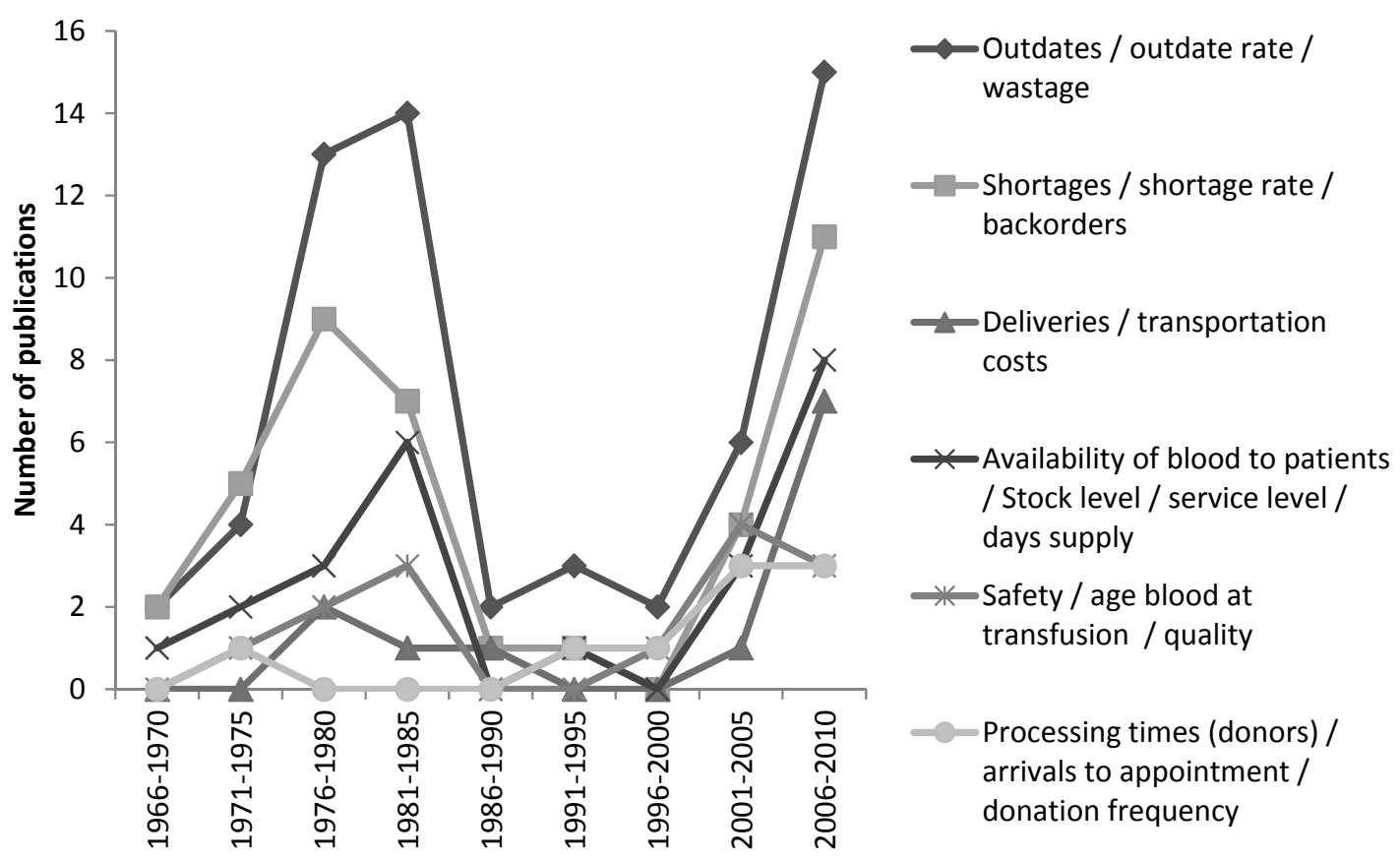

Figure 10: Trends in objective

\section{Practical implementation/case studies}

The majority of the papers feature practical implementations or case studies. Papers using real data as input were also placed into this category. A more rigorous classification in this field might be possible, though our classification can give a rough idea of the distribution of papers according to this criterion.

Benziger et al. (95) describe the type of blood bank and transfusion service they have developed at a small hospital in a rural area. Their system is based on a large list of pretested, known and available donors who can be contacted quickly to supply blood upon demand, a system which facilitates the maintenance of only limited blood supplies. They describe their system as a walking blood bank and appear to achieve satisfactory results using it. Denesiuk et al. (30) discuss the implementation of a redistribution system for near-outdate red blood cell units. The paper considers both information about the transportation material and the method that is used. A comprehensive list of examples can be found in Table 9.

Table 9 - Practical implementation/case studies 
6)(34)(68)(82)(7)(4)(75)(59)(63)(42)(39)(50)(40)(71)(96)

$(3)(44)(91)(23)(25)(86)(27)(80)(70)(90)(29)(33)(12)(87)(49)(28$

no

)$(78)(85)(93)(52)(61)(31)(19)(64)(5)(24)(26)(66)(69)(77)(2)(60$ )$(45)(79)(72)$

Figure 11 represents the trends in papers reporting on a practical implementation and/or case study versus the theoretic papers describing a model without applying it to real-life data. We observe a clear trend towards papers describing a real-life application of the presented methodologies. Based on this observation, our forecast is that in the (near) future papers involving real-life data and/or implementations will continue to outnumber papers without any empirical testing.

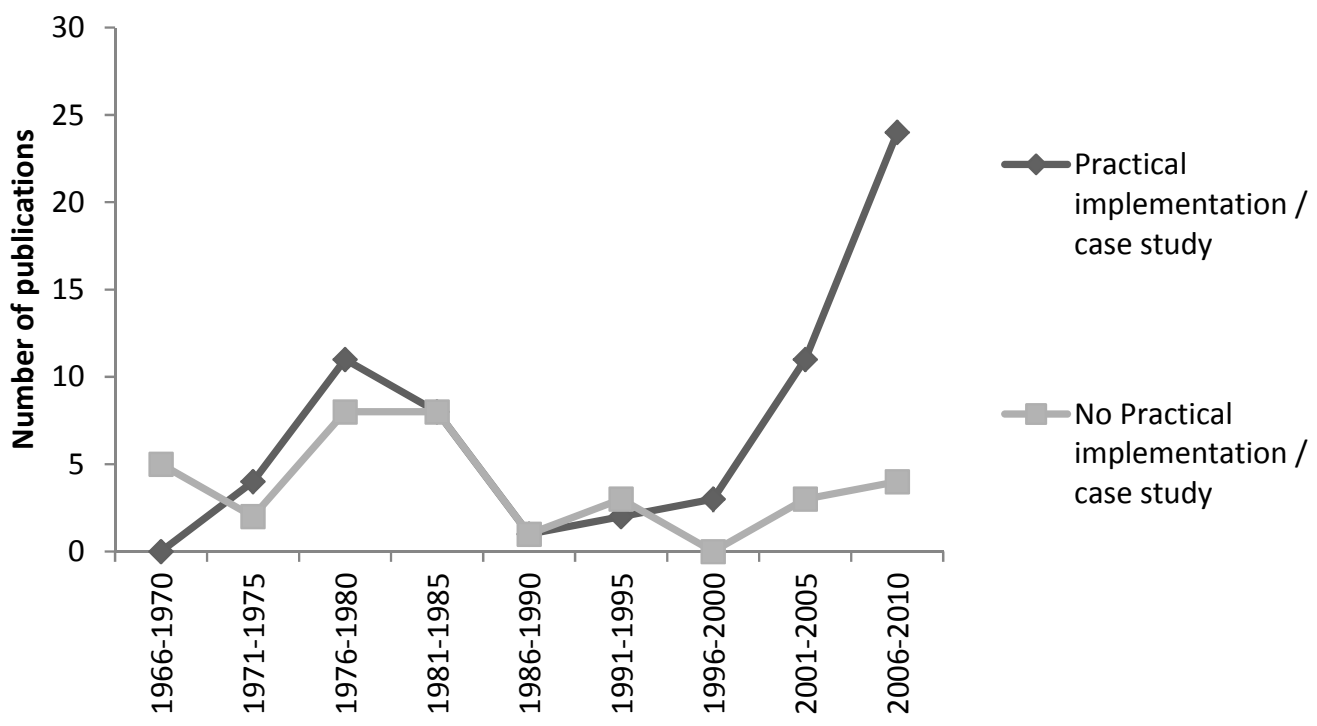

Figure 11: Trends in practical implementations / case studies

\section{Discussion}

Our research has led to the detection of some facts and trends that initially were not expected. One surprising find is that the use of a frozen blood reserve is less adequate than one would expect, and that other policies are more efficient in sustaining a firm supply of blood products. A frozen blood reserve can prove useful in isolated cases and is more appropriate for products such as plasma than for other products. Red blood cells, on the other hand, are the component that is most often associated with the term 'blood'. The overall tendency, as observed by Hess, (8) is that the freezing of red blood cells will continue to exist, but at a decreasing rate. 
The PLT ordering problem was extensively covered in both Haijema et al. (41) and van Dijk et al.(42). At first, their contribution seemed to close a gap in the literature. However, Blake (44) showed that wrong assumptions were made in these papers and that further research is necessary to develop robust and fast heuristics in order to solve the PLT inventory problem.

Worth mentioning is the prominence of papers that concern the supply of blood, often taking human factors into account. These papers relate to the blood supply chain problem in an indirect way, though we deem their inclusion appropriate, considering the special characteristics of blood products in terms of supply.

When considering the classification by type of approach, we observe that only seven papers are set in a deterministic setting, whereas 42 papers are set in a stochastic setting. This outcome is remarkable though understandable, since stochastic settings mimic the practical environment more truthfully.

Performance measures that dominate the literature are outdating-related and shortage-related. This is a result we expected, though we would point out that measures concerning safety/quality are not negligible either. Measures related to the latter are not always taken into account when defining policies, though in practice safety is the most important factor. The fact that a loss of life is generally unacceptable, gives safety priority over all costs in the supply chain. Most papers acknowledge this, warning that the policy results could be toned down when practical implementation occurs.

To conclude, we would emphasize that most papers feature some form of practical implementation or case study. Although our classification in terms of this criterion could have been more rigorously applied, this observation identifies the tendency of testing policy results in practice.

\section{Conclusion}

In this paper, we have reviewed the literature on the inventory and supply chain management of blood products. We have tried to identify different perspectives in terms of which to classify the existing manuscripts. The literature is classified according to five different types of blood products (section 2): red blood cells, blood platelets, plasma, whole blood and frozen blood. Another perspective we used to establish a classification is the solution method (section 3). We distinguished between 12 different approaches to finding a solution. The third perspective applies to the hierarchical level of decisionmaking (section 4), where the papers are placed into three different categories. Section 5 provides a classification based on type of problem. A distinction was made between inbound problems and outbound problems. In section 6, we examined the type of approach used in the literature. Most papers for which this classification perspective is relevant appear to feature a stochastic approach, while only a few papers are set in a deterministic setting. Papers dealing with optimization problems were classified into two categories depending on whether they delivered an exact solution procedure or rely on heuristic approaches (section 7). Section 8 provides a classification based on the performance 
measures that are focused on. The performance measures were aggregated in a meaningful way, leading to six distinct categories. In section 9 we evaluated to what extent practical implementations or case studies occur. We concluded that the majority of papers feature some form of practical implementation or case study. Each perspective is presented as a table in which the classification is displayed. The classification choices are exemplified through the citation of key references or by expounding the features of the perspective. The main contribution of this review is to facilitate the tracing of published work in relevant fields of interest, as well as identifying trends and indicating which areas should be subject to future research.

\section{References}

1. Katsaliaki, Korina. Cost-effective practices in the blood service sector. Health Policy. 2008, Vol. 86, pp. 276-287.

2. Schreiber, George B.;Schlumpf, Karen S.;Glynn, Simone A.;Wright, David J.;Yongling, Tu;King, Melissa R.;Higgins, Martha J.;Kessler, Debra;Gilcher, R.;Nass, Catharie C.;Guiltan, Anne M.

Convenience, the bane of our existence, and other barriers to donating. Transfusion. 2006, Vol. 46, 4, pp. 545553.

3. Pierskalla, William P. Supply chain management of blood banks. [ed.] M.L. Brandeau, F. Sainfort and W.P. Pierskalla. Operations research and health care: A handbook of methods and applications. s.l. : Kluwer Academic Publishers, 2004, pp. 103-145.

4. Rytilä, Jyrki S.;Spens, Karen M. Using simulation to increase efficiency in blood supply chains. Management Research News. 2006, Vol. 29, 12, pp. 801-819.

5. Nahmias, S. Perishable inventory theory: a review. Operations research. 1982, Vol. 30, 4, pp. 680-780.

6. Prastacos, Gregory P. Blood inventory management: an overview of theory and practice. Management Science. 1984, Vol. 30, 7, pp. 777-800.

7. Rautonen, Jukka. Redesigning supply chain management together with the hospitals. Transfusion. 2007, Vol. 47, 2, pp. 197S-200S.

8. Hess, John R. Red cell freezing and its impact on the supply chain. Transfusion Medicine. 2004, Vol. 14, 1, pp. 1-8.

9. Erickson, Michelle L.;Champion, Melanie H.;Klein, Roger;Ross, Rebecca L.;Neal, Zena M.;Snyder, Edward L. Management of blood shortages in a tertiary care academic medical center: the Yale-New Haven Hospital frozen blood reserve. Transfusion. 2008, Vol. 48, 10, pp. 2252-2263.

10. Pereira, A. Economies of scale in blood banking: a study based on data envelopment analysis. Vox Sanguinis. 2006, Vol. 90, 4, pp. 308-315.

11. Kendall, Kenneth E. Formulating blood rotation policies with multiple objectives. Management Science. 1980, Vol. 26, 11, pp. 1145-1157.

12. Dumas, M. Barry;Rabinowitz, Manus. Policies for reducing blood wastage in hospital blood banks. Management Science. 1977, Vol. 23, 10, pp. 1124-1132.

13. Brodheim, Eric;Prastacos, Gregory P. The Long Island blood distribution system as a prototype for regional blood management. Interfaces. 1979, Vol. 9, 5, pp. 3-20.

14. Kamp, Christel;Heiden, Margarethe;Henseler, Olaf;Seitz, Rainer. Management of blood supplies during an influenza pandemic. Transfusion. 2010, Vol. 50, 1.

15. Heddle, Nancy M.;Liu, Yang;Barty, Rebecca;Webert, Kathryn E.; Whittaker, Susan;Gagliardi, Kate;Lauzon, Deborah;Owens, Wendy. Factors affecting the frequency of red blood cell outdates: an approach to establish benchmarking targets. Transfusion. 2009, Vol. 49, 2, pp. 219-226.

16. Perera, G.;Hyam, C.;Taylor, C.;Chapman, J.F. Hospital blood inventory practice: the factors affecting stock level and wastage. Transfusion Medicine. 2009, Vol. 19, 2, pp. 99-104.

17. Kopach, Renata. Tutorial on constructing a red blood cell inventory management system with two demand rates. European Journal of Operational Research. 2008, Vol. 185, 3, pp. 1051-1059.

18. Pitocco, Christine;Sexton, Thomas R. Alleviating blood shortages in a resource-constrained environment. Transfusion. 2005, Vol. 45, 7, pp. 1118-1126.

19. Madden, Erin;Murphy, Edward L.;Custer, Brian. Modeling red cell procurement with both double-redcell and whole-blood collection and the impact of European travel deferral on units available for transfusion.

Transfusion. 2007, Vol. 47, 11, pp. 2025-2037. 
20. Davis, Rodeina;Geiger, Bradley;Gutierrez, Alfonso;Heaser, Julie;Veeramani, Dharmaraj. Tracking blood products in blood centres using radio frequency identification: a comprehensive assessment. Vox Sanguinis. 2009, Vol. 97, 1, pp. 50-60.

21. Chapman, J.F.;Cook, R. The Blood Stocks Management Scheme, a partnership venture between the National Blood Service of England and North Wales and participating hospitals for maximizing blood supply chain management. Vox Sanguinis. 2002, Vol. 83, 2, pp. 239-246.

22. Kendall, Kenneth E. Planning for innovation in health care: a breakthrough in blood banking. Long Range Planning. 1984, Vol. 17, 6, pp. 127-131.

23. Brodheim, Eric; Derman, C.; Prastacos, G. On the evaluation of a class of inventory policies for perishable products such as blood. Management Science. 1975, Vol. 21, 11, pp. 1320-1325.

24. Pegels, C. Carl; Jelmert, Andrew E. An evaluation of blood inventory policies: a markov chain application. Operations Research. 1970, Vol. 18, 6, pp. 1087-1098.

25. Brodheim, Eric; Hirsch, R.; Prastacos, G. Setting inventory levels for hospital blood banks. Transfusion. 1976, Vol. 16, 1, pp. 63-70.

26. Pereira, A. Blood inventory management in the type and screen era. Vox Sanguinis. 2005, Vol. 89, 4, pp. 245-250.

27. Chapman, J.F. Unlocking the essentials of effective blood inventory management. Transfusion. 2007, Vol. 47, pp. 190S-196S.

28. Friedman, B.A.; Abbott, R.D.; Williams, G.W. A blood ordering strategy for hospital blood banks derived from a computer-simulation. American Journal of clinical pathology. 1982, Vol. 78, 2, pp. 154-160.

29. Cumming, P.D.; Kendall, K.E.; Pegels, C.C.; Seagle, J.P.; Shubsda, J.F. A collections planning model for regional blood suppliers: description and validation. Management Science. 1976, Vol. 22, 9, pp. $962-971$.

30. Denesiuk, Lisa; Richardson, Trevor; Nahirniak, Susan; Clarke, Gwen. Implementation of a redistribution system for near-outdate red blood cell units. Archives of Pathology \& Laboratory Medicine. 2006, Vol. 130, 8, pp. 1178-1183.

31. Kaspi, H.; Perry, D. Inventory systems of perishable commodities. Advances in applied probability. 1983, Vol. 15, 3, pp. 674-685.

32. Pegels, C. Carl; Seagle, J.P.; Cumming, P.C.; Kendall, K.E.; Shubsda, J.F. An analysis of selected blood service policy changes. Medical care. 1977, Vol. 15, 2, pp. 147-157.

33. Cumming, P.D.; Kendall, K.E.; Pegels, C.C.; Seagle, J.P. Cost-effectiveness of use of frozen blood to alleviate blood shortages. Transfusion. 1977, Vol. 17, 6, pp. 602-606.

34. Prastacos, Gregory P.; Brodheim, E. PBDS: a decision support system for regional blood management. Management Science. 1980, Vol. 26, 5, pp. 451-463.

35. Napier, J.A.; Biffin, A. The importance of crossmatch/transfusion ratio and intervals between successive crossmatches in determining red cell outdate rates. Clinical and Laboratory Haematology. 1983, Vol. 5, 4, pp. 379-385.

36. Galloway, M.J.; Jane, G.; Sudlow, L.; Trattles, J.; Watson, J.;. A tabletop exercise to assess a hospital emergency blood management contingency plan in a simulated acute blood shortage. Transfusion Medicine. 2008, Vol. 18, 5, pp. 302-307.

37. Georgsen, J.; Kristensen, T. From serological to computer crossmatching in nine hospitals. Vox Sanguinis. 1998, Vol. 74, Supplement 2, pp. 419-425.

38. Novis, D.A.; Renner, S.; Friedman, R.; Walsh, M.K.; Saladino, A.J. Quality indicators of blood utilization: three College of American Pathologists Q-Probes studies of 12,288,404 red cell units in 1639 hospitals. Archives of Pathology and Laboratory Medicine. 2002, Vol. 126, 2, pp. 150-156.

39. Delen, D.; Erraguntla, M.; Mayer, R.J.; Wu, C.-N. Better management of blood supply-chain with GISbased analytics. Annals of Operations Research, Article in Press. 2009.

40. Mustafee, N.; Taylor, S.J.E.; Katsaliaki, K.; Brailsford, S. Facilitating the analysis of a UK national blood service supply chain using distributed simulation. Simulation. 2009, Vol. 85, 2, pp. 113-128.

41. Haijema, Rene;van Dijk, Nico;van der Wal, Jan;Sibinga, Cees Smit. Blood platelet production with breaks: optimization by SDP and simulation. International Journal of Production Economics. 2009, Vol. 121, 2, pp. 464-473.

42. van Dijk, Nico;Haijema, Rene;van der Wal, Jan;Sibinga, Cees Smit. Blood platelet production: a novel approach for practical optimization. Transfusion. 2009, Vol. 49, 3, pp. 411-420.

43. Fontaine, Magali J.;Chung, Yenho T.;Rogers, William M.;Sussmann, Harry D.; Quach, Peter;Galel, Susan A.;Goodnough, Lawrence T.;Erhun, Feryal. Improving platelet supply chains through collaborations between blood centers and transfusion services. Transfusion. 2009, Vol. 49, 10, pp. 2040-2047.

44. Blake, John T. On the use of operational research for managing platelet inventory and ordering. Transfusion. 2009, Vol. 49, 3, pp. 396-401.

45. Sirelson, V.; Brodheim, E. A computer planning model for blood platelet production and distribution. Computer methods and programs in biomedicine. 1991, Vol. 35, 4, pp. 279-291. 
46. Katz, A.J.; Carter, C.W.; Saxton, P.; Blutt, J.; Kakaiya, R.M. Simulation analysis of platelet production and inventory management. Vox Sanguinis. 1983, Vol. 44, 1, pp. 31-36.

47. Critchfield, G.C.; Connelly, D.P.; Ziehwein, M.S.; Olesen, L.S.; Nelson, C.E.; Scott, E.P. Automatic prediction of platelet utilization by time series analysis in a large tertiary care hospital. American journal of clinical pathology. 1985, Vol. 85, 5, pp. 627-631.

48. Ledman, R.E.; Groh, N. Platelet production planning to ensure availability while minimizing outdating. Transfusion. 1984, Vol. 24, 6, pp. 532-533.

49. Friedberg, R.C. Clinical and laboratory factors underlying refractoriness to platelet transfusions. Journal of Clinical Apheresis. 1996, Vol. 11, 3, pp. 143-148.

50. Ghandforoush, P.; Sen, T.K. A DSS to manage platelet production supply chain for regional blood centers. Decision Support Systems, Article in Press. 2010.

51. Melnyk, Steven A.;Pagell, Mark;Jorae, Gail;Sharpe, A. Spencer. Applying survival analysis to operations management: analyzing the differences in donor classes in the blood donation process. Journal of Operations Management. 1995, Vol. 13, 4, pp. 339-356.

52. Jagannathan, Raj;Sen, Tarun. Storing crossmatched blood: a perishable inventory model with prior allocation. Management Science. 1991, Vol. 37, 3, pp. 251-266.

53. Custer, B.;Johnson, E.S.;Sullivan, S.D.;Hazlet, T.K.;Ramsey, S.D.;Murphy, E.L.;Busch, M.R.

Community blood supply model: development of a new model to assess the safety, sufficiency, and cost of the blood supply. Medical decision making. 2005, Vol. 25, 5, pp. 571-582.

54. Bosnes, Vidar;Aldrin, Magne;Heier, Hans Erik. Predicting blood donor arrival. Transfusion. 2005, Vol. 45, 2, pp. 162-170.

55. Custer, Brian; Johnson, Eric S.;Sulliivan, Sean D.;Hazlet, Tom K.;Ramsey, Scott D.;Hirschler, Nora V.;Murphy, Edward L.;Busch, Michael P. Quantifying losses to the donated blood supply due to donor deferral and miscollection. Transfusion. 2004, Vol. 44, 10, pp. 1417-1426.

56. Godin, Gaston;Conner, Mark;Sheeran, Paschal;Bélanger-Gravel, Ariane;Germain, Marc.

Determinants of repeated blood donation among new and experienced blood donors. Transfusion. 2007, Vol. 47, 9, pp. 1607-1615.

57. James, R.C.;Matthews, D.E. Analysis of blood donor return behaviour using survival regression methods. Transfusion Medicine;. 1996, Vol. 6, 1, pp. 21-30.

58. Chung, K.H.;Lin, C.K.;Chan, J.S.K.;Lee, C.K. Predicting potential drop-out and future commitment for first-time donors based on first 1.5-year donation patterns: the case in Hong Kong Chinese donors. Vox Sanguinis. 2007, Vol. 93, 1, pp. 57-63.

59. Schreiber, George B.;Sharma, U.K.;Wright, D.J.;Glynn, S.A.;Ownby, H.E.;Tu, Y.;Garratty, G.;Piliavin, J.;Zuck, T.;Gilcher, R. First year donation patterns predict long-term commitment for first-time donors. Vox Sanguinis. 2005, Vol. 88, 2, pp. 114-121.

60. Sheeran, P.;Conner, M.;Germain, M.;Blondeau, D.;Gagne, C.;Beaulieu, D.;Naccache, H. Factors explaining the intention to give blood among the general population. Vox Sanguinis. 2005, Vol. 89, 3, pp. 140149.

61. Jennings, J.B. An analysis of hospital blood bank whole blood inventory control policies. Transfusion. 1968, Vol. 8, 6, p. 335.

62. Glynn, Simone A.; Busch, Michael P.; Schreiber, George B.; Murphy, Edward L.; Wright, David J.; Tu, Yongling; Kleinman, Steven H. Effect of a national disaster on blood supply and safety: the September 11 Experience. Journal of the American Medical Association. 2003, Vol. 289, 17, pp. 2246-2253.

63. Sonmezoglu, M.; Kocak, N.; Oncul, O.; Ozbayburtlu, S.; Hepgul, Z.; Kosan, E.; Aksu, Y.; Bayik, M. Effects of a major earthquake on blood donor types and infectious diseases marker rates. Transfusion Medicine. 2005, Vol. 15, 2, pp. 93-97.

64. Michaels, J.D.; Brennan, J.E.; Golden, B.L.; Fu, M.C. A simulation study of donor scheduling systems for the American Red Cross. Computers \& Operations Research. 1993, Vol. 20, 2, pp. 199-213.

65. Jennings, J.B. Blood bank inventory control. Management Science. 1973, Vol. 19, 6, pp. 637-645.

66. Pierskalla, William P.; Roach, Chris D. Optimal issuing policies for perishable inventory. Management Science. 1972, Vol. 18, 11, pp. 603-614.

67. Frankfurter, George M.; Kendall, K.E.; Pegels, C.C. Management control of blood through short-term supply-demand forecast system. Management Science. 1974, Vol. 21, 4, pp. 444-452.

68. Prastacos, Gregory P. Optimal myopic allocation of a product with fixed lifetime. Journal of the operational Research Society. 1978, Vol. 29, 9, pp. 905-913.

69. - . Allocation of a perishable product inventory. Operations Research. 1981, Vol. 29, 1, pp. 95-107.

70. Cohen, M.A.; Pierskalla, W.P.; Sassetti, R.J. The impact of adenine and inventory utilization decisions on blood inventory management. Transfusion. 1983, Vol. 23, 1, pp. 54-58.

71. Cohen, M.A.; Pierskalla, W.P. Management Policies for a Regional Blood Bank. Transfusion. 1975, Vol. 15, 1, pp. 57-67. 
72. Cohen, M.A.; Nahmias, S.; Pierskalla, W.P. A Feedback Inventory Model of a Hospital Blood Bank. Proceedings of the 7th Annual Pittsburgh Conference, University of Pittsburgh. 1976, Vol. 7, pp. 612-616. 73. Kahn, R.A.; McDonough, B.; Rowe, A.; Ellis, F.R.; Pino, B. The impact of converting to an all frozen blood system in a large regional blood center. Transfusion. 1978, Vol. 18, 3, pp. 304-311.

74. Hemmelmayr, Vera;Doerner, Karl F.;Hartl, Richard F.;Savelsbergh, Martin W.P. Delivery strategies for blood products supplies. OR Spectrum. 2009, Vol. 31, 4, pp. 707-725.

75. Sahin, Güvenç;Meral, Sedef;Süral, Haldun. Locational analysis for regionalization of Turkish Red Crescent blood services. Computers \& Operations Research. 2007, Vol. 34, 3, pp. 692-704.

76. Hemmelmayr, Vera. Vendor managed inventory for environments with stochastic product usage. European Journal of Operational Research. 2010, Vol. 202, 3, pp. 686-695.

77. Sapountzis, C. Allocating blood to hospitals from a central blood bank. European Journal of Operational Research. 1984, Vol. 16, 2, pp. 157-162.

78. Gregor, P.J.; Forthofer, R.N.; Kapadia, A.S. An evaluation of inventory and transportation policies of a regional blood distribution system. European Journal of Operational Research. 1982, Vol. 10, 1, pp. 106-113.

79. Vrat, P.; Khan, A.B. Simulation of a blood-inventory-bank system in a hospital. Socio-Economic Planning Sciences. 1976, Vol. 10, 1, pp. 7-15.

80. Cohen, M.A.; Pierskalla, W.P. Target inventory levels for a hospital blood-bank or a decentralized blood banking system. Transfusion. 1979, Vol. 19, 4, pp. 444-454.

81. Carden, Robert; DelliFraine, Jami L. An examination of blood center structure and hospital customer satisfaction: what can centralized and decentralized blood centers learn from each other? Health Marketing Quarterly. 2005, Vol. 22, 3, pp. 21-42.

82. Rabinowitz, M. Blood bank inventory policies: a computer simulation. Health services research. 1973, Vol. 8, 4, pp. 271-282.

83. Katsaliaki, Korina; Brailsford, S.C. Using simulation to improve the blood supply chain. Journal of the Operational Research Society. 2007, Vol. 58, 2, pp. 219-227.

84. Pink, J.; Thomson, A.; Wylie, B. Inventory management in Sydney-Public-Hospital blood banks. Transfusion Medicine. 1994, Vol. 4, 3, pp. 237-242.

85. Hirsch, R.L.; Brodheim, E.; Ginsberg, F.E. A computer-based blood inventory and information system for hospital blood banks as part of a regional blood management system. Transfusion. 1970, Vol. 10, 4, pp. 194202.

86. Catassi, C.A.; Peterson, E.L. The blood inventory control system - helping blood bank management through computerized inventory control. Transfusion. 1967, Vol. 7, 1, pp. 60-69.

87. Federgruen, Awi; Prastacos, Gregory P.; Zipkin, Paul H. An allocation and distribution model for perishable products. Operations Research. 1986, Vol. 34, 1, pp. 75-82.

88. Kendall, Kenneth E. Multiple objective planning for regional blood centers. Long Range Planning. 1980, Vol. 13, 4, pp. 98-104.

89. Brodheim, Eric; Prastacos, Gregory P. A regional blood management system with prescheduled deliveries. Transfusion. 1979, Vol. 19, 4, pp. 455-462.

90. Cohen, M.A.; Pierskalla, W.P.; Sassetti, R.J.; Consolo, J. An overview of a hierarchy of planning models for regional blood bank management. Transfusion. 1979, Vol. 19, 5, pp. 526-534.

91. Britten, A.F.; Geurtze, D.G. Weekly rotation of blood inventory - a system for supplying small hospitals. Transfusion. 1979, Vol. 19, 6, pp. 738-741.

92. Dodds, A.J.; Pun, A.; Isbister, J.P.; Ting, A.; Klarkowski, D.; Concannon, A.J.; Biggs, J.C. A rational approach to crossmatching blood for elective surgery. Anaesthesia and Intensive Care. 1983, Vol. 11, 1, pp. 1619.

93. Hirsch, R.L.; Cazal, P. Recommendations of the task force on record-keeping and blood distribution systems. Vox Sanguinis. 1981, Vol. 40, 3, pp. 216-221.

94. Hirsch, R.L.; Brodheim, E. Blood distribution systems and the exchange of information between hospital blood banks and regional blood centers. Vox Sanguinis. 1981, Vol. 40, 3, pp. 239-244.

95. Benziger, M.; Benziger, J.; Canfield, T.M. Blood banking in the small hospital. Surgical Clinics of North America. 1979, Vol. 59, 3, pp. 471-482.

96. Or, I.; Pierskalla, W.P. A Transportation Location-Allocation Model for Regional Blood Banking. AIIE Transactions. 1979, Vol. 11, 2, pp. 86-92.

97. Axelrod, F.B.; Grindon, A.J.; Vroon, D.H. Disproportionate outdating of group A blood. Transfusion. 1987, Vol. 27, 3, pp. 219-221.

98. Elston, R.C.; Pickrel, J.C. A statistical approach to ordering and usage policies for a hospital blood bank. Transfusion. 1963, Vol. 3, 1, p. 41. 